\title{
Synthesis and Characterization of new Ethoxylated Carbohydrate based Surfactants for Corrosion Inhibition of low LCS Steel in Aqueous Solutions
}

\author{
Abd El-Aziz S. Fouda 1,* ${ }^{\mathbb{C}}$, Samir A. Abd El-Maksoud ${ }^{2}$, Ahmed T. El-Habab ${ }^{3}$, Ahmed R. Ibrahim ${ }^{4}(\mathbb{D}$ \\ 1 Department of Chemistry, Faculty of Science, Mansoura University, Mansoura-35516, Egypt; asfouda@hotmail.com \\ (A.E.A.S.F.); \\ 2 Department of Chemistry, Faculty of Science, Port Said University, Port Said, Egypt; samirabdelhady@yahoo.com \\ (S.A.A.E.M.); \\ 3 Section Head Chemist in Khalda petroleum company, Egypt; ahmed.taher@khalda-eg.com (A.T.E.H.); \\ 4 Department of Chemistry, Faculty of Science, Sultan Qaboos University, P.O. Box 36, Postal Code 123, Muscat, Oman; \\ * Correspondence: a.ramadan1991@yahoo.com;
}

Scopus Author ID 56231506400

Received: 11.06.2020; Revised: 3.09.2020; Accepted: 6.09.2020; Published: 13.09.2020

\begin{abstract}
The heterocyclic compounds, mainly carbohydrate-based surfactant, 1, 4 Sorbitan, namely (Sorbitan Mono-stearate with 20 moles of Ethylene oxide SMS-20-EO, Sorbitan Mono-oleate SMO, and Sorbitan Mono-oleate ethoxylated with 20 moles of Ethylene oxide SMO-20-EO ) have been synthesized and characterized through different spectroscopic methods (FTIR, ${ }^{1} \mathrm{H}$ NMR). Then estimated as corrosion inhibitors of low LCS (LCS) in the aggressive environment $1 \mathrm{M} \mathrm{HCl}$ utilizing a weight loss (WL), the destructive and destructive electrochemical techniques. The surface examination was tested using several techniques. The new ethoxylated carbohydrate-based surfactant gave an excellent inhibition performance (IE \%). The adsorption of the inhibitors obeys the Langmuir adsorption model. The metal dissolution and inhibitor adsorption phenomena have been studied via the estimation of thermodynamic parameters, which describe the adsorption properties of SMO, SMO-20EO, and SMS-20-EO.
\end{abstract}

Keywords: Synthesis; Characterization; Corrosion inhibition; Low LCS; $\mathrm{HCl}$ and Carbohydrate based surfactant.

(C) 2020 by the authors. This article is an open-access article distributed under the terms and conditions of the Creative Commons Attribution (CC BY) license (https://creativecommons.org/licenses/by/4.0/).

\section{Introduction}

The advantages of using surfactants as corrosion inhibitors are due to they yield high inhibition efficiency [1], easily produced in a large scale, low toxicity, and low price [2]. Predominantly, the inhibitory action of surfactant molecules in aqueous solution may be attributed to chemisorption or electrostatic physical adsorption onto the metallic surface [3]. The development of surfactants based on natural renewable resources is a concept that is gaining recognition from different industries $[5,6]$. Carbohydrate-based surfactants are the final result of a product concept that is based on the greatest possible use of renewable resources. Whereas the derivatization of fats and oils to produce a variety of different surfactants for a broad range of applications has a long tradition and is well established, the production of surfactants based on fats, oils, and carbohydrates on a larger industrial scale is relatively new $[7,8]$. The structure of a typical surfactant with a hydrophilic head group and a hydrophobic tail always attach a carbohydrate molecule as a perfect polar head. Due to its 
many hydroxyl groups, in fat and oil derivatives $[9,10]$. Sugar surfactants have several rather flexible properties. A class of carbohydrate-derived surfactants, called sorbitan esters (anhydrous sorbitol), is derived from sorbitol, a hexitol produced by the catalytic reduction of glucose. In acidic conditions, sorbitol is dehydrated to sorbitan and even further to bicyclic isosorbide. Several authors have used surfactants as corrosion inhibitors for CS (LCS) and MS (mild steel) in $\mathrm{HCl}$ solution [11-22]. Sorbitan fatty acid ester surfactants can be produced by a direct or indirect industrial process (Fig. 1).

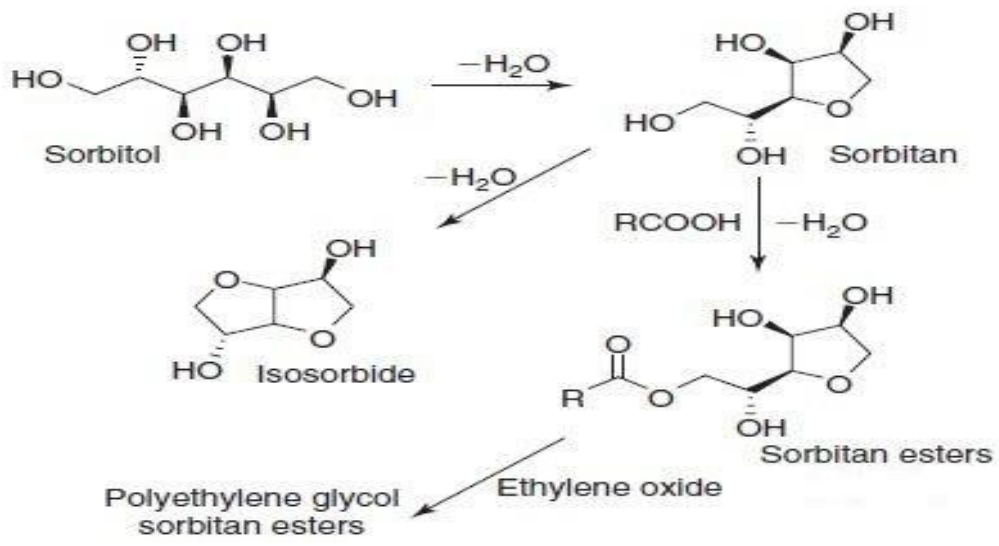

Figure 1 Synthesis of sorbitan esters by intramolecular dehydration of sorbitol in the presence of acid at 150$200^{\circ} \mathrm{C}$ and subsequent base-catalyzed esterification with fatty acids at $200-250^{\circ} \mathrm{C}$.

The aim of this paper is to synthesize and characterize some sorbitan fatty esters and ethoxylated sorbitan fatty esters as carbohydrate-based surfactants, and to calculate the inhibition efficiency of these surfactants for LCS corrosion in $1 \mathrm{M} \mathrm{HCl}$ electrolytes by electrochemical, weight loss, and Surface analysis techniques.

\section{Materials and Methods}

The experiment was carried out with LCS with the following composition per weight $\%$ is shown in Table 1; rectangular specimens with dimensions $2 \times 2 \times 0.2 \mathrm{~cm}$ were used for WL measurements. For electrochemical tests, the exposed surface area of LCS was prepared as $1 \mathrm{~cm}^{2}$.

Table 1. Composition in weight $\%$ of LCS.

\begin{tabular}{l|l|l|l|l|l|l|l|l} 
Elements & $\mathbf{C}$ & $\mathbf{C r}$ & $\mathbf{N i}$ & $\mathbf{S i}$ & $\mathbf{M n}$ & $\mathbf{P}$ & $\mathbf{S}$ & $\mathbf{F e}$ \\
\hline $\begin{array}{l}\text { Composition } \\
\text { (Weight \%) }\end{array}$ & 0.14 & 0.1 & 0.01 & 0.024 & 0.5 & 0.05 & 0.05 & Reset
\end{tabular}

\subsection{Chemicals and solutions.}

The investigated carbohydrate-based surfactant named Sorbitan Mono-stearate with 20 moles of Ethylene oxide SMS-20-EO, Sorbitan Mono-oleate SMO, and Sorbitan Mono-oleate ethoxylated with 20 moles of ethylene oxide SMO-20-EO. The new surfactants are easily soluble in methanol and dimethyl sulfoxide, which have high molecular weights, and contain many donating atoms. The aggressive electrolytes used were prepared from $37 \% \mathrm{HCl}$. Appropriate Concentrations of acid was prepared using twice distilled water. Prepared concentrations of pervious new surfactants are $25,50,75,100$, and $125 \mathrm{ppm}$ in $1 \mathrm{M} \mathrm{HCl}$ aggressive media. All the materials are AR grade. 


\subsection{Synthesis of carbohydrate-based surfactants.}

\subsubsection{Synthesis of sorbitan mono-oleate.}

The synthesis is carried out in two steps:

Step 1 (Preparation of anhydrous sorbitol):

207.8 grams from Sorbitol 70\% Aqueous Solution (D-Glucitol) and 2.6 grams of activated charcoal powder DARCO G 60 AR were charged into a round-bottom 500-mL 4necked flask equipped with a reflux condenser, stainless steel stirrer, and 2 feed streams separated, vacuum gauge, Vacuum Pump. The evacuation of the reactor system was carried out to a pressure of about $6 \mathrm{~mm}$ of mercury and raising the temperature to $95^{\circ}-100{ }^{\circ} \mathrm{C}$ in order to remove the water present in the sorbitol. 1.5 grams of p-toluene sulfonic acid catalyst will be charged to the reactor system after all the aqueous solvent was removed. The P-toluene sulfonic acid function is to allow the reaction to go to completion at a lower temperature. Then evacuating the reactor system is carried out again and then heating to $150^{\circ} \mathrm{C}$. After the addition is complete, stirring is continued at a constant temperature for 130 minutes. Then, cooling of the reaction mixture was carried out, then, 0.35 gram of sodium hydroxide and 0.7 gram of Hyflosupercel diatomaceous earth Powder were added. Hyflosupercel was used as a filtration agent and also used as a clarifying agent. The reactants then were agitated for 20 minutes, and filtration at about $100^{\circ}-120^{\circ} \mathrm{C}$ under an inert nitrogen atmosphere was carried through a sintered glass filter funnel (Scheme 1) [23-25].
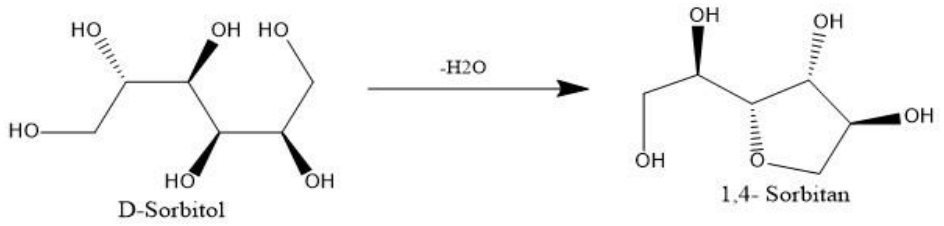

Scheme 1. The chemical synthesis pathway of anhydrosorbitol or 1,4-Sorbitan.

Step 2 (Preparation of sorbitan mono-oleate):

27.8 grams from Anhydro sorbitol that was prepared in the first step, 36.3 grams from commercial Industrene $\AA 106$ Oleic Acid supplied by Chemtura, 0.15 gram from powdered sodium hydroxide, and 0.9 gram of activated charcoal powder DARCO G 60 AR, were charged into a round-bottom 500-mL 4-necked flask equipped with a reflux condenser, stainless steel stirrer, and 2 feed streams separated. The reaction mixture was purged with inert nitrogen gas and then heating the reactants at atmospheric pressure to $205^{\circ} \mathrm{C}$. for 45 minutes. Maintaining the reaction mixture at the predetermined temperature and pressure was carried out for 360 minutes while maintaining a slight flow of inert nitrogen gas. Cooling the reaction mixture was then carried out and was then left standing overnight. Heating of the reaction mixture in the next morning was then carried out to $105^{\circ} \mathrm{C}$. while maintaining a slight flow of inert nitrogen gas, then treatment of the reaction mixture with 0.30 grams of $85 \%$ phosphoric acid for neutralization of the product and 0.30 gram of Hyflosupercel diatomaceous earth Powder. The reactants then were agitated for 20 minutes, and filtration at about $100^{\circ}-120^{\circ} \mathrm{C}$ under an inert nitrogen atmosphere was carried through a sintered glass filter funnel [26].

Finally, the product (Scheme 2) was bleached with $0.5 \%$ (from the total weight of the product) Hyprox TM 500, which is a 50\% Aqueous solution of Hydrogen Peroxide, and then filtration for the product again is carried out in the presence of Hyflosupercel diatomaceous earth Powder. 


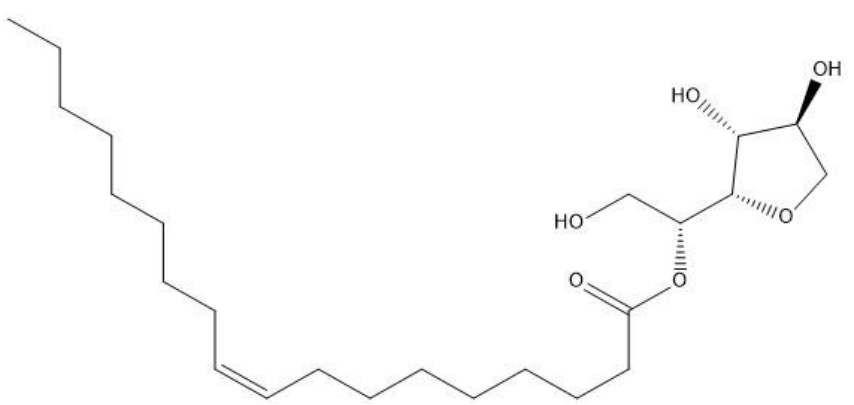

Scheme 2. The chemical structure of the prepared Sorbitan Mono-oleate surfactant and is designated as SMO.

\subsubsection{Synthesis of sorbitan monostearate.}

The synthesis is carried out in two steps:

Step 1 (Preparation of anhydrous sorbitol):

207.8 grams from Sorbitol 70\% Aqueous Solution (D-Glucitol) and 2.6 grams of activated charcoal powder DARCO G 60 AR were charged into a round-bottom 500-mL 4necked flask equipped with a reflux condenser, stainless steel stirrer, and 2 feed streams separated, vacuum gauge, Vacuum Pump. The evacuation of the reactor system was carried out to a pressure of about $6 \mathrm{~mm}$ of mercury and raising the temperature to $95^{\circ}-100{ }^{\circ} \mathrm{C}$ in order to remove the water present in the sorbitol. 1.5 grams of p-toluenesulfonic acid catalyst will be charged to the reactor system after all the aqueous solvent was removed. The P-toluene sulfonic acid function is to allow the reaction to go to completion at a lower temperature). Then evacuating the reactor system is carried out again and then heating to $150^{\circ} \mathrm{C}$. After the addition is complete, stirring is continued at a constant temperature for 80 minutes. Then, cooling of the reaction mixture was carried out, then, 0.35 gram of sodium hydroxide and 0.7 gram of Hyflosupercel diatomaceous earth Powder were added. Hyflosupercel was used as a filtration agent and also used as a clarifying agent. The reactants then were agitated for 20 minutes, and filtration at about $100^{\circ}-120^{\circ} \mathrm{C}$ under an inert nitrogen atmosphere was carried through a sintered glass filter funnel [27].

Step 2 (Preparation of sorbitan monostearate):

64.8 grams from Anhydro sorbitol that was prepared in the first step, 144.2 grams from commercial Industrene ${ }^{\circledR} 9018$ FG Stearic Acid, 0.5 gram from powdered sodium hydroxide, and 1.9 grams of A fine black decolorizing Activated charcoal powder DARCO G $60 \mathrm{AR}$, were charged into a round-bottom 500-mL 4-necked flask equipped with a reflux condenser, stainless steel stirrer, and 2 feed streams separated. The reaction mixture was purged with inert nitrogen gas and then heating the reactants at atmospheric pressure to $205^{\circ} \mathrm{C}$. For one hour. Maintaining the reaction mixture at the predetermined temperature and pressure was carried out for 240 minutes while maintaining a slight flow of inert nitrogen gas. Cooling the reaction mixture was then carried out and was then left standing overnight. Heating of the reaction mixture in the next morning was then carried out to $105^{\circ} \mathrm{C}$. while maintaining a slight flow of inert nitrogen gas, then treatment of the reaction mixture with 0.80 grams of $85 \%$ phosphoric acid for neutralization of the product and 0.80 gram of Hyflosupercel diatomaceous earth Powder. The reactants then were agitated for 20 minutes, and filtration at about $100^{\circ}-120^{\circ} \mathrm{C}$ under an inert nitrogen atmosphere was carried through a sintered glass filter funnel [28].

Finally, the product (Scheme 3) was bleached with $0.5 \%$ (from the total weight of the product) Hyprox TM 500, which is a 50\% Aqueous solution of Hydrogen Peroxide, and then filtration for the product again is carried out in the presence of Hyflosupercel diatomaceous earth Powder. 


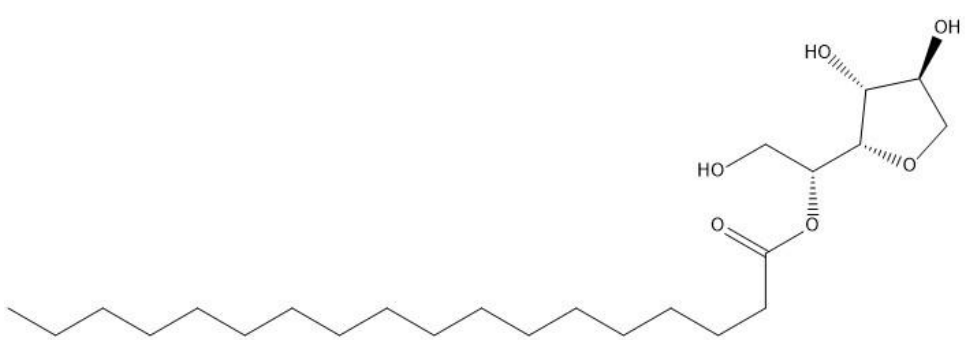

Scheme 3. The chemical structure of the prepared Sorbitan Monostearate surfactant and is designated as SMS.

\subsubsection{Ethoxylation of sorbitan monooleate and sorbitan monostearate surfactants.}

The synthesis of Sorbitan Monooleate and Sorbitan Mono-stearate ethoxylated with 20 moles of Ethylene oxide gas was conducted in a 2-L autoclave as carried out in our previous publication [29].

The previously prepared Sorbitan Monooleate or Sorbitan Mono-stearate was charged into a high-pressure stainless steel autoclave with $\mathrm{KOH}(1.0 \mathrm{wt} . \%)$ as a catalyst at $130{ }^{\circ} \mathrm{C}$ with continuous stirring while passing a stream of nitrogen gas through the system for $10 \mathrm{~min}$ to flush out the air. The nitrogen stream was then closed and replaced by a molar ratio of 20 units of ethylene oxide (EO) gas. The reaction completion was accepted when the pressure reached its minimum value. At this stage, heating was stopped, and the vessel contents were cooled. After cooling, the product obtained was neutralized with acetic acid. The yield was then collected. The obtained surfactants (Scheme 4, 5) appeared as a colorless viscous liquid appearance.

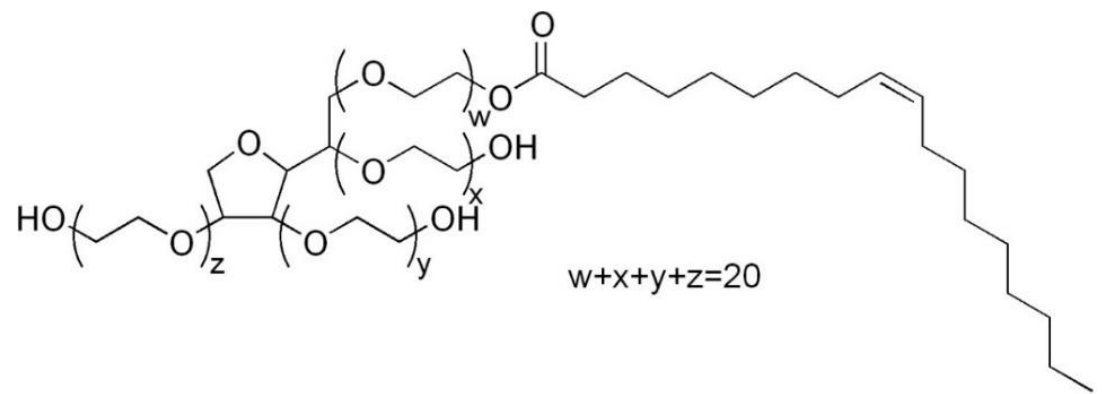

Scheme 4. The chemical structure of sorbitan monooleate ethoxylated with 20 moles of ethylene oxide and is designated as SMO-20-EO.

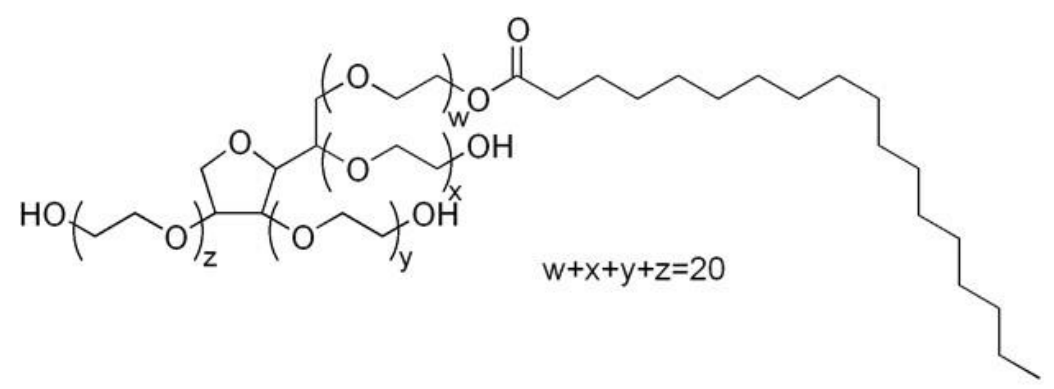

Scheme 5. The chemical structure of sorbitan monostearate ethoxylated with 20 moles of ethylene oxide and is designated as SMS-20-EO.

\subsection{Characterization of the new ethoxylated carbohydrate-based surfactants.}

2.3.1. Spectroscopic investigation of the prepared new ethoxylated carbohydrate-based surfactants.

The chemical structures of the prepared new Ethoxylated carbohydrate-based surfactants were confirmed by the FTIR and 1HNMR spectra. FTIR was carried out using the 
Pye Unicam SP1200 spectrophotometer using the KBr Wafer technique in the region from 4000 to $500 \mathrm{Cm}^{-1}$. ${ }^{1} \mathrm{H}-\mathrm{NMR}$ spectra were determined on BRUKER $400 \mathrm{MHZ}$ (D- DMSO) using TMS as an internal standard (chemical shift in d-scale).

\subsubsection{Color.}

Gardner Colorimeter was used to measure the color, and the results were expressed as Gardner units (GU).

\subsubsection{Acid number.}

ASTM D974-92 method is used to determine the Acid Number of the prepared surfactants, and the results were expressed in $\mathrm{mg}$ ( $\mathrm{KOH}$ equivalent).g (sample)-1

\subsubsection{Hydroxyl number.}

ASTM E326-85 method is used to determine the Hydroxyl Number of the prepared surfactants, and the results were expressed in $\mathrm{mg}$ ( $\mathrm{KOH}$ equivalent).g (sample)-1

\subsubsection{Saponification number.}

Saponification Number was measured to determine the Hydroxyl Number of the prepared surfactants, and the results were expressed in $\mathrm{mg}$ (KOH equivalent).g (sample)-1

\subsubsection{Surface tension measurements and determination of CMC.}

The surface tension measurements were undertaken for different concentrations of the prepared new Ethoxylated carbohydrate-based surfactants dissolved in double distilled water with a surface tension equal $72 \mathrm{mN} \mathrm{m}-1$ at $25{ }^{\circ} \mathrm{C}$ according to the method described in ASTM Designation: D1331-89 with a Krüss Tensiometer using a Du Nouy ring at constant temperature $\left(25 \pm 1{ }^{\circ} \mathrm{C}\right)$. Apparent surface tension values were given as a mean of three consecutive measurements.

The critical micelle concentrations (CMC) value of the prepared new Ethoxylated carbohydrate-based surfactants were determined using surface tension measurements where surface tension values of aqueous solutions of our prepared surfactants were plotted against the corresponding concentrations. The interrupt change in the surface tension-concentrations curves will express the critical micelle concentration.

\subsection{Corrosion inhibition investigation measurements.}

\subsubsection{Chemical measurements (WL).}

Six parallel coins of LCS sheets $2 \times 2 \times 0.2 \mathrm{~cm}$ were prepared by emery paper (grade 320-600-800-1200), washed by distilled water and acetone. After accurate weighing, the specimens were dipped in a $150 \mathrm{ml}$ beaker, which contained $100 \mathrm{ml}$ of $\mathrm{HCl}$ with and without the addition of different concentrations of SMS-20-EO, SMO, and SMO-20-EO. All aggressive acid solutions were open to the air. During 3 hours, the specimens were taken out, washed, dried, and weighed accurately by Four-Digit Analytical Balance. The average (WL) of the six parallel coins LCS sheets could be obtained. The \% IE and the degree of surface coverage $\theta$, of non-ionic surfactant for the corrosion of LCS in $1 \mathrm{M} \mathrm{HCl}$ were calculated from eq. (1) [30]:

$$
\text { IE } \%=\theta \times 100=\left[1-\left(\mathrm{W} / \mathrm{W}^{\circ}\right)\right] \times 100
$$


Where $\mathrm{W}^{\circ}$ and $\mathrm{W}$ are the values of the average WLs without and with the addition of the surfactant, respectively

\subsubsection{Electrochemical measurements.}

The electrochemical instruments are Gamry Instrument Potentiostat/ Galvanostat/ ZRA (PCI4-G750) were performed by three electrodes working electrode is LCS, Pt electrodes as an auxiliary electrode, and calomel as a reference electrode (SCE). For the Tafel polarization technique, the potential of $\pm 1.1 \mathrm{~V}$ was applied with a scan rate of $0.5 \mathrm{mVs}^{-1}$. EIS study was carried out with the frequency range between 100 to $0.2 \mathrm{~Hz}$ using a $5 \mathrm{mV}$ amplitude. EFM experiments were performed by applying a potential perturbation signal with amplitude $10 \mathrm{mV}$ with two sine waves of 2 and $5 \mathrm{~Hz}$ [31].

\subsubsection{Surface examinations.}

The coins of LCS used for surface examination were immersed in $1 \mathrm{M} \mathrm{HCl}$ in the absence and the presence of $125 \mathrm{ppm}$ of new ethoxylated surfactant at $25^{\circ} \mathrm{C}$ for $24 \mathrm{hrs}$. The analysis was performed using a Scanning Electron Microscope (JEOL JSM-5500, Japan).

\section{Results and Discussion}

\subsection{Characterization of the New Prepared Ethoxylated Carbohydrate Based Surfactants.}

3.1.1. Spectroscopic investigation of the newly prepared ethoxylated carbohydrate-based surfactants.

A: FTIR Spectra of the new prepared Ethoxylated carbohydrate-based surfactants:

Figure $1 \mathrm{a}, \mathrm{b}$, c shows FTIR spectrograms of SMO, SMO-20-EO, and SMS-20-EO surfactants, respectively. The structural moieties for the newly prepared ethoxylated carbohydrate-based surfactants that can be justified spectroscopically by infrared spectroscopy are summarized as following [32]. At $3000 \mathrm{~cm}^{-1}(\mathrm{O}-\mathrm{H})_{\text {associated }}$ stretching vibrations, $2900-$ $3000 \mathrm{~cm}^{-1}(\mathrm{sp} 3 \mathrm{C}-\mathrm{H})$ stretching vibrations, $1700 \mathrm{~cm}^{-1}(\mathrm{C}=\mathrm{O})$ Carbonyl groups, $1400 \mathrm{~cm}^{-1}\left(\mathrm{CH}_{2}\right)$ aliphatic sp3 stretching vibrations and $1100 \mathrm{~cm}^{-1}(\mathrm{C}-\mathrm{O})$ ether and alcohols Bending vibrations.

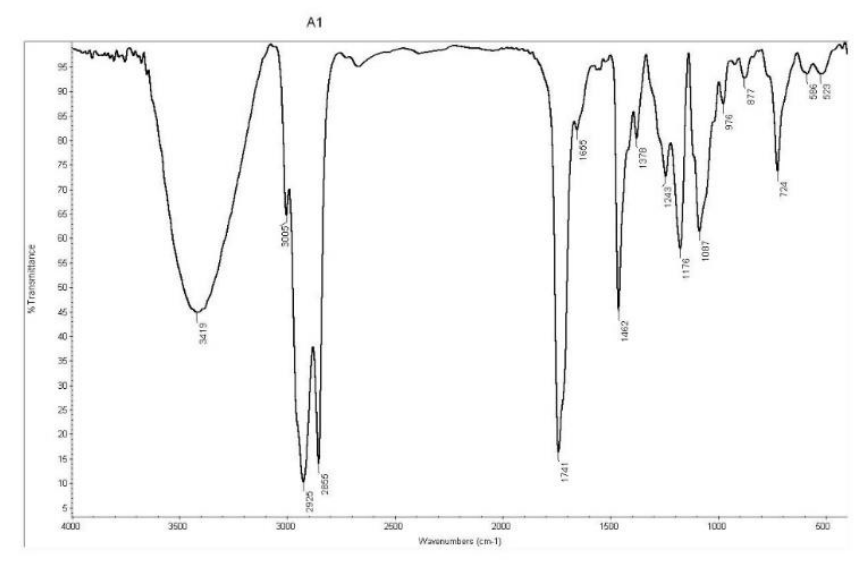

Figure 1. (a) FTIR spectrograms of SMO (A1). 


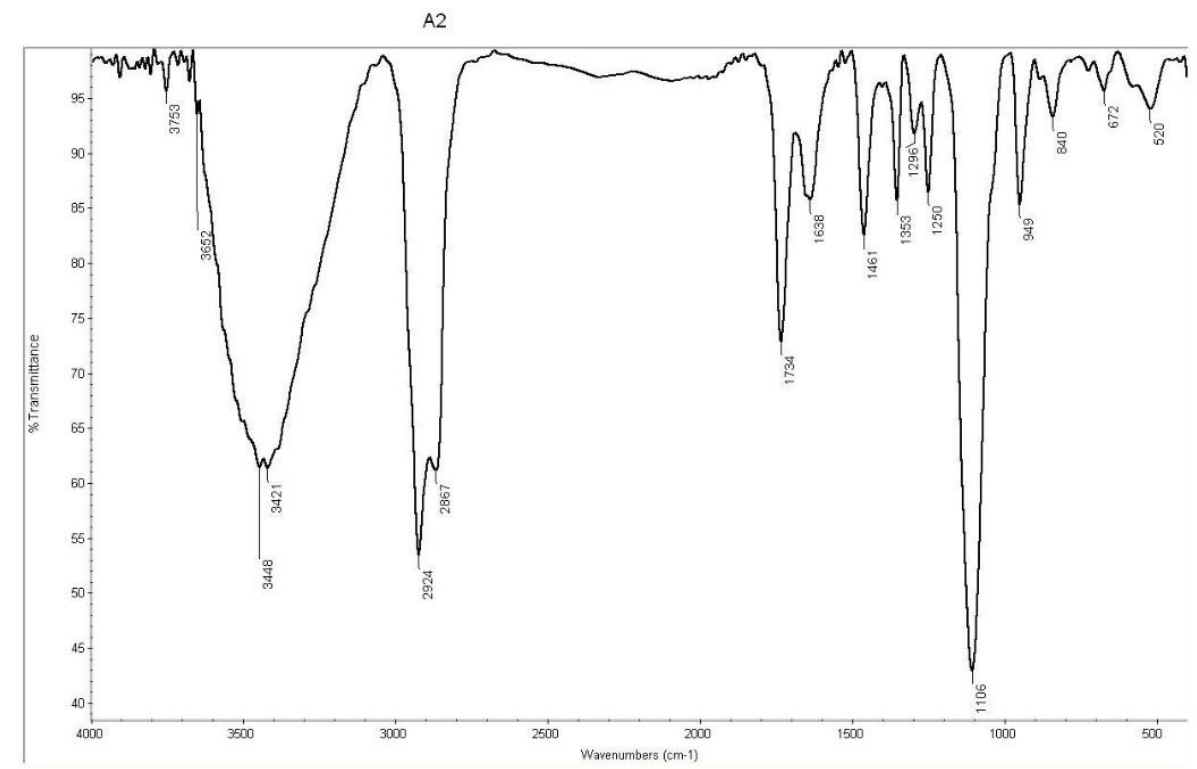

Figure 1. (b) FTIR spectrograms of SMO-20-EO (A2).

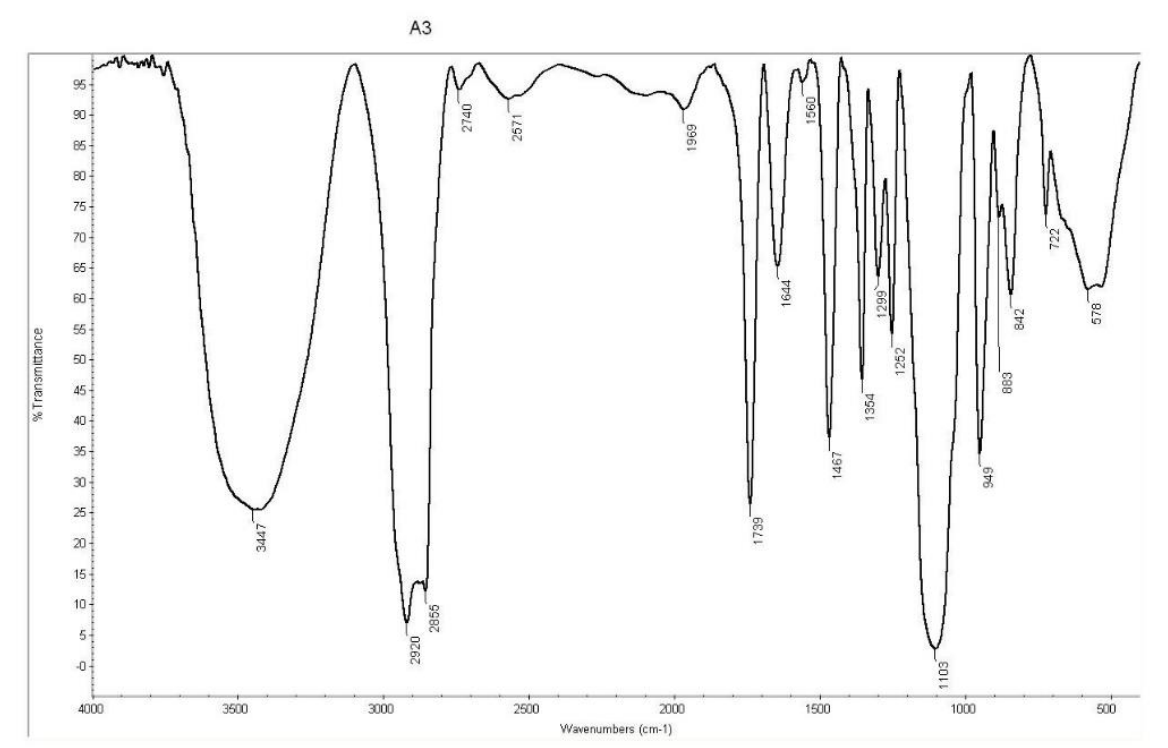

Figure 1. (c) FTIR spectrograms of SMS-20-EO (A3).

B: ${ }^{1} \mathrm{H}$ NMR Spectra of the new prepared Ethoxylated carbohydrate-based surfactants:

Figure 2a, b, c represents ${ }^{1} \mathrm{H}$ NMR spectrograms of SMS-20-EO, SMO, SMO-20-EO surfactants, respectively.

(SMO) compound: ${ }^{1} \mathrm{H}-\mathrm{NMR}(400 \mathrm{MHz})(\mathrm{DMSO} \mathrm{d} 6) \delta$ 0.6013-0.6320 (t, $\left.\mathrm{CH}_{3}\right), 1.0026$ (s, $\left.\mathrm{CH}_{2}\right), 1.2362-1.2707$ (t, $\left.\mathrm{CH}_{2}\right), 1.7379-1.7512(\mathrm{~m}, \mathrm{CH}), 1.9070-1.9434$ (t, 2CH), 2.0471 (s, $\mathrm{CH}_{2}$ ), 2.2714 (s, $\mathrm{CH}_{2}$ ), 3.1132-3.1747 broad overlap (m, $\mathrm{CH}_{2}$ ), 5.0877 (s, OH). (SMO-20-EO) compound: ${ }^{1} \mathrm{H}-\mathrm{NMR}\left(400 \mathrm{MHz}\right.$ ) (DMSO d6) $\delta$ 0.8450-0.8614 (t, $\left.\mathrm{CH}_{3}\right), 1.2429\left(\mathrm{~s}, \mathrm{CH}_{2}\right)$, $1.4999\left(\mathrm{t}, \mathrm{CH}_{2}\right), 1.9793-2.0241(\mathrm{~m}, \mathrm{CH}), 2.1751-2.2106(\mathrm{t}, 2 \mathrm{CH}), 2.2922-2.3087(\mathrm{t}, 3 \mathrm{CH})$, 3.4033-3.5940 broad overlap ( $\left.\mathrm{m}, \mathrm{CH}_{2}\right), 5.3181$ (s, OH), $8.1448(\mathrm{~s}, \mathrm{OH})$.

(SMS-20-EO) compound: ${ }^{1} \mathrm{H}-\mathrm{NMR}(400 \mathrm{MHz})(\mathrm{DMSO} \mathrm{d} 6) \delta 0.8604\left(\mathrm{~s}, \mathrm{CH}_{3}\right), 1.2401$ (s, $\left.\mathrm{CH}_{2}\right), 1.5133$ (t, $\left.\mathrm{CH}_{2}\right), 2.2891(\mathrm{~m}, \mathrm{CH}), 3.4037-3.5923$ broad overlap ( $\left.\mathrm{m}, \mathrm{CH}_{2}\right), 8.1450$ (s, $\mathrm{OH})$. Both FTIR and ${ }^{1} \mathrm{H}$ NMR results can provide evidence of the synthesis of the novel nonionic surfactants is successful. 


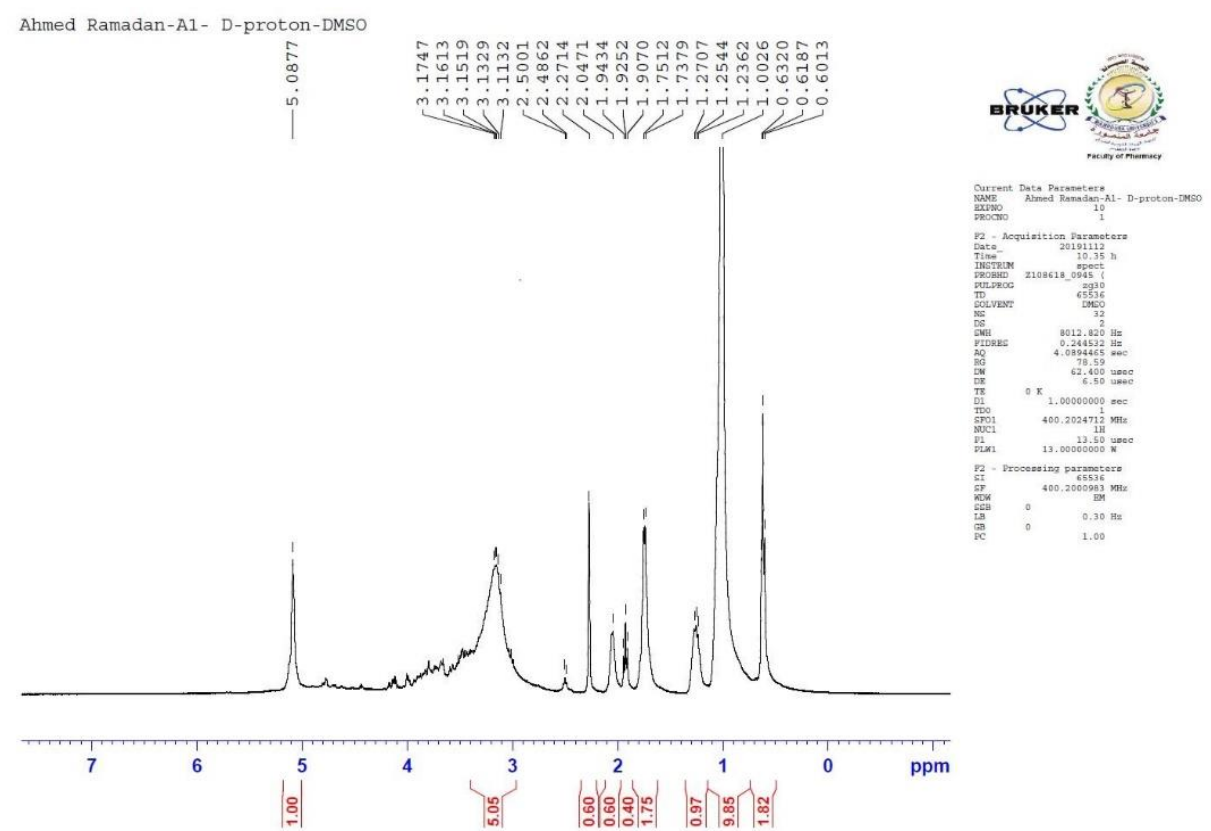

Figure 2. (a) ${ }^{1} \mathrm{H}$ NMR spectra of SMO surfactant in DMSO.

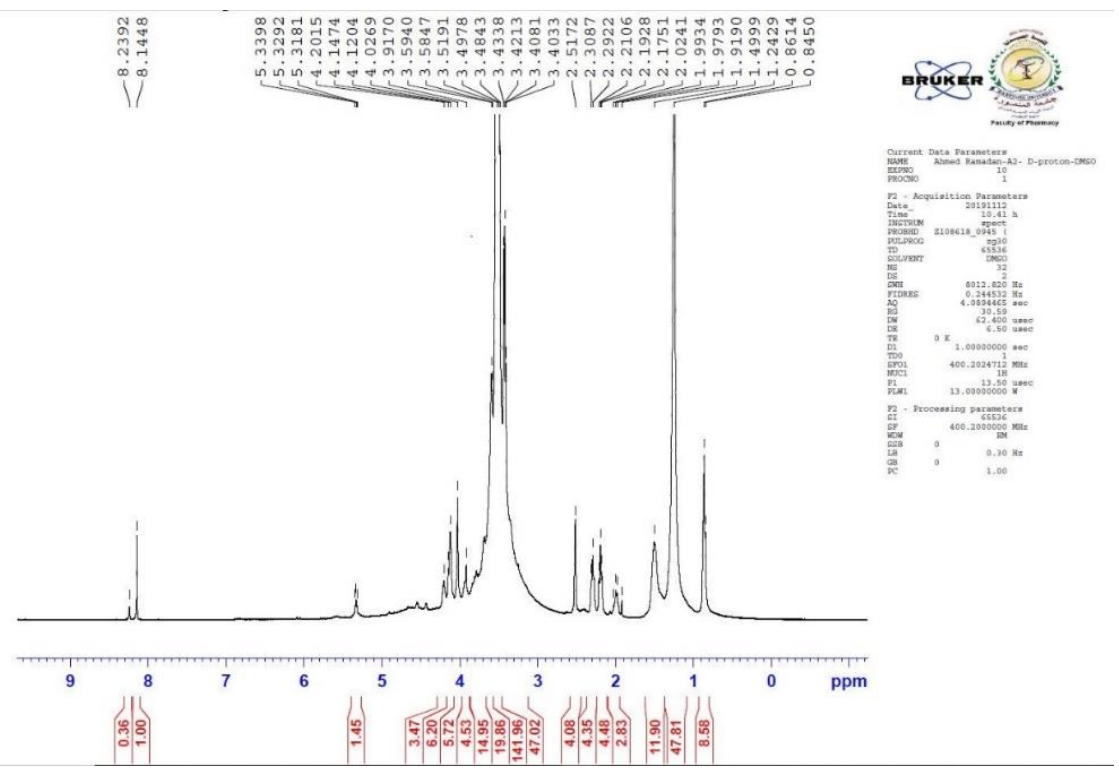

Figure 2. (b) ${ }^{1} \mathrm{H}$ NMR spectra of SMO-20-EO surfactant in DMSO.

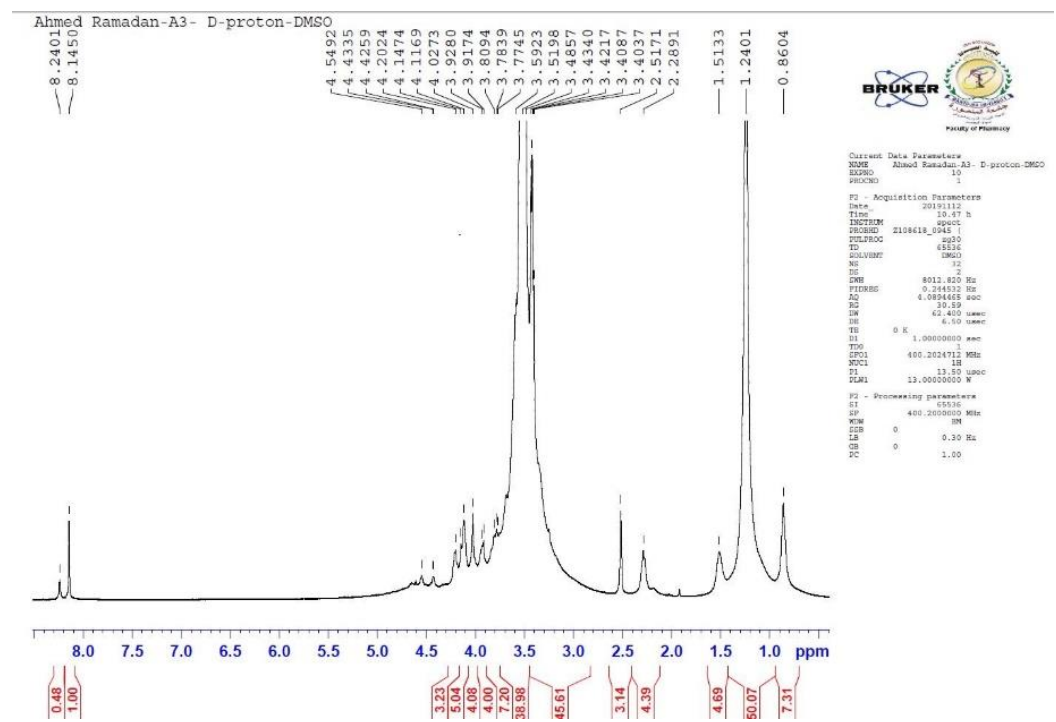

Figure 2. (c) ${ }^{1} \mathrm{H}$ NMR spectra of SMS-20-E surfactant in DMSO. 
3.1.2. Physical and chemical characterization of the newly prepared ethoxylated carbohydratebased surfactants.

All properties are summarized in Table 2:

Table 2. Physical and chemical characterization of the newly prepared Ethoxylated carbohydrate-based surfactants.

\begin{tabular}{l|c|c|c|c} 
Surfactant / Test Method & SMO & SMS & SMO-20-EO & SMS-20-EO \\
\hline Color & 7 & $<1$ & $<1$ & $<1$ \\
\hline Acid Number & 3.3 & 9 & 2 & 2.2 \\
\hline Hydroxyl Number & 199 & 235 & 74 & 87 \\
\hline Saponification Number & 154 & 151 & 53 & 49
\end{tabular}

3.1.3. Surface tension measurements and determination of CMC.

The surface tension (c) of water originates from hydrogen bonds between the water molecules at the air-water interface. If the surfactant adsorbs at the interface, it breaks the hydrogen bonds, and consequently, the surface tension of the water surface will decrease lower than $71.8 \mathrm{mN} \mathrm{m}^{-1}$ at $25^{\circ} \mathrm{C}$. Here, the surface tension of surfactants was measured for different concentrations of the newly prepared Ethoxylated carbohydrate-based surfactants above and below the critical micelle concentration (CMC).

Figure $3 \mathrm{a}, \mathrm{b}$, c represents plots of surface tension versus concentration for the new prepared Ethoxylated carbohydrate-based surfactants in deionized water. The surface tension curve shows an obvious descending as the concentration of aqueous surfactant solution increases.

This means that the surfactant molecules are highly adsorbed at the water interface. As long as the concentration of the surfactant molecules increases, the surface tension values will remain stable. When these two regions are intercepted, this gives the concentration at which the surfactant micelles are formed (CMC). This observation was recorded for the newly prepared Ethoxylated carbohydrate-based surfactants up to the $\mathrm{CMC}$, beyond which no considerable changes were noticed. The CMC data obtained from the intercept in the concentration plots is shown in Table 3. The ethylene oxide EO molecules increase the hydrophilicity of the non-ionic surfactants due to the ether bond leads to increasing CMC values and increasing in the depression of the surface tension at this concentration.

Table 3. Surface tension $(\gamma)$ and critical micelle concentration $\left(\mathrm{C}_{\mathrm{cmc}}\right)$ of the newly prepared Ethoxylated carbohydrate-based surfactants from surface tension measurements at $25{ }^{\circ} \mathrm{C}$.

\begin{tabular}{l|c|c} 
Surfactant & $\gamma$ Surface tension $\left(\mathbf{m N m}^{-1}\right)$ & $\mathbf{C M C}, \mathbf{p p m}$ \\
\hline SMO & 28.7 & 125 \\
\hline SMO-20-EO & 34.5 & 250 \\
\hline SMS-20-EO & 37.2 & 700
\end{tabular}

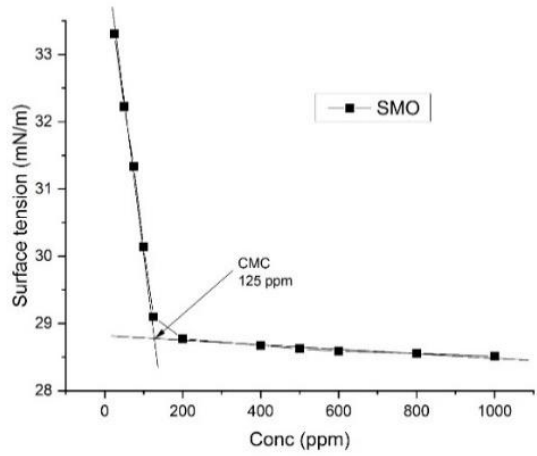

Figure 3. (a) Surface tension of SMO surfactant versus its concentrations in water at $25^{\circ} \mathrm{C}$. 


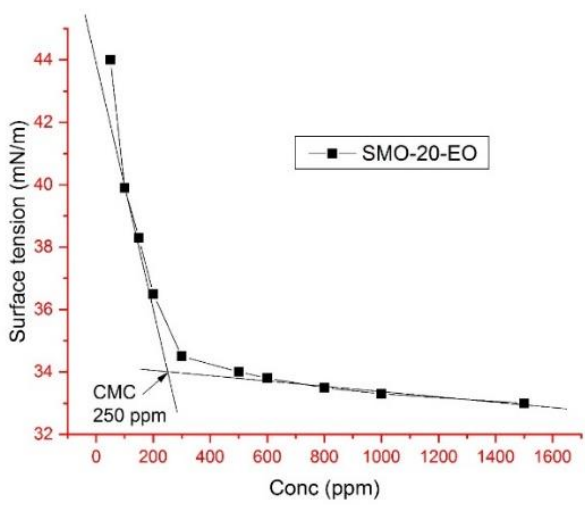

Figure 3. (b) Surface tension of SMO-20-EO surfactant versus its concentrations in water at $25{ }^{\circ} \mathrm{C}$.

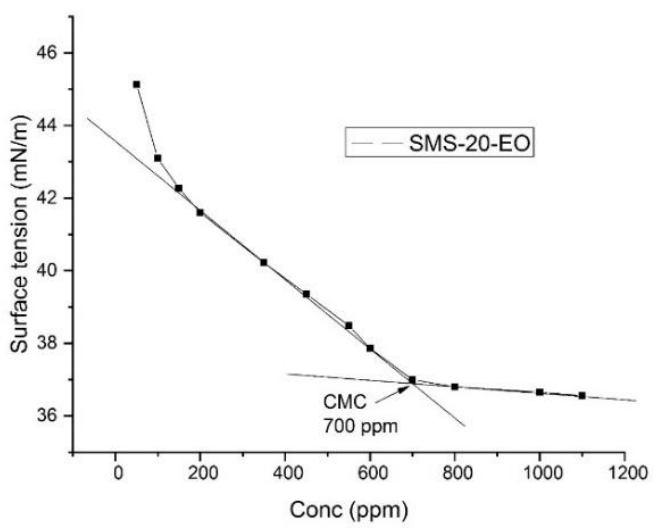

Figure 3. (c) Surface tension of SMS-20-EO surfactant versus its concentrations in water at $25^{\circ} \mathrm{C}$.

\subsection{WL measurements.}

WL of LCS was determined, at various time intervals, in the absence and presence of a different concentration of surfactants (SMS-20-EO, SMO, and SMO-20-EO). The increase in the surfactant concentration was accompanied by a decrease in WL and an increase in the \%IE. These results lead to the conclusion that new surfactants under investigation are fairly efficient inhibitors for LCS dissolution in $\mathrm{HCl}$ solution. Also, the surface coverage $(\Theta)$ while $\theta=\frac{I E \%}{100}$ by the surfactants, would increase with increasing the surfactant conc. Corrosion Rate (C.R) in $\mathrm{mg} \mathrm{cm}{ }^{-2} \mathrm{~min}^{-1}$ is decreased with the increase of the surfactant concentration. These results are summarized in Table 4.

\subsubsection{Effect of temperature.}

The effect of temperature on the corrosion rate of LCS in $1 \mathrm{M} \mathrm{HCl}$ and with the absent and presence of different surfactant conc. was studied in the temperature range of $25-45{ }^{\circ} \mathrm{C}$ uses WL measurements. As corrosion rate (C.R.) increases, the temperature is increased, and the IE\% of the surfactants decreases as shown in Table 4. The adsorption behavior of surfactants on the LCS surface occurs through physical adsorption.

Table 4. Values of IE\% and (C.R.) of surfactants (SMO\&SMO-20-EO\&SMS-20-EO) for the corrosion of LCS in $1 \mathrm{M} \mathrm{HCl}$ from WL measurements at different concentrations and a temperature range of $25-45^{\circ} \mathrm{C}$.

\begin{tabular}{|c|c|c|c|c|c|c|c|c|c|c|}
\hline [Inh.] ppm & \multicolumn{2}{|c|}{$298 K$} & \multicolumn{2}{|c|}{ 303K } & \multicolumn{2}{|c|}{ 308K } & \multicolumn{2}{|c|}{ 313K } & \multicolumn{2}{|c|}{$318 K$} \\
\hline SMO & C.R & $\% \mathrm{IE}$ & C.R & $\% \mathrm{IE}$ & C.R & $\% \mathrm{IE}$ & C.R & $\% \mathrm{IE}$ & C.R & $\% \mathrm{IE}$ \\
\hline 25 & 0.0120 & 66 & 0.0413 & 77 & 0.0268 & 80 & 0.04 & 83 & 0.023 & 86 \\
\hline
\end{tabular}




\begin{tabular}{l|c|c|c|c|c|c|c|c|c|c}
\hline \multirow{2}{*}{ [Inh.] ppm } & \multicolumn{2}{c}{$\mathbf{2 9 8 K}$} & \multicolumn{2}{c}{$\mathbf{3 0 3 K}$} & \multicolumn{2}{c}{$\mathbf{3 0 8 K}$} & \multicolumn{2}{c}{ 313K } & \multicolumn{2}{c}{ 318K } \\
\hline 50 & 0.0095 & 74 & 0.0321 & 84 & 0.0213 & 86 & 0.0287 & 88 & 0.0159 & 90 \\
\hline 75 & 0.0077 & 85 & 0.0243 & 80 & 0.0174 & 87 & 0.0232 & 90 & 0.0121 & 92 \\
\hline 100 & 0.0048 & 91 & 0.0197 & 84 & 0.0134 & 90 & 0.0160 & 93 & 0.0093 & 94 \\
\hline 125 & 0.003 & 94 & 0.0165 & 87 & 0.0089 & 93 & 0.0085 & 94 & 0.0043 & 95 \\
\hline SMO-20-EO & C.R & $\%$ IE & C.R & $\%$ IE & C.R & $\%$ IE & C.R & $\%$ IE & C.R & $\%$ IE \\
\hline 25 & 0.0096 & 80 & 0.028 & 82 & 0.0401 & 83 & 0.0205 & 85 & 0.0065 & 87 \\
\hline 50 & 0.0083 & 83 & 0.0222 & 86 & 0.0302 & 87 & 0.0166 & 88 & 0.0055 & 89 \\
\hline 75 & 0.0073 & 88 & 0.0165 & 89 & 0.0228 & 90 & 0.0133 & 91 & 0.0042 & 92 \\
\hline 100 & 0.0063 & 90 & 0.0110 & 91 & 0.0160 & 92 & 0.0091 & 93 & 0.0033 & 94 \\
\hline 125 & 0.0041 & 93 & 0.0072 & 94 & 0.0095 & 95 & 0.0059 & 96 & 0.0022 & 97 \\
\hline SMS-20-EO & C.R & $\%$ IE & C.R & $\%$ IE & C.R & $\%$ IE & C.R & $\%$ IE & C.R & $\%$ IE \\
\hline 25 & 0.0102 & 79 & 0.0107 & 83 & 0.0292 & 80 & 0.0212 & 86 & 0.0295 & 87 \\
\hline 50 & 0.0093 & 81 & 0.0084 & 82 & 0.025 & 86 & 0.0161 & 90 & 0.0218 & 91 \\
\hline 75 & 0.0083 & 83 & 0.0075 & 84 & 0.0208 & 88 & 0.0117 & 93 & 0.0163 & 93 \\
\hline 100 & 0.0064 & 87 & 0.0063 & 88 & 0.0166 & 90 & 0.0068 & 95 & 0.00943 & 96 \\
\hline 125 & 0.0045 & 89 & 0.0038 & 91 & 0.0093 & 93 & 0.0043 & 94 & 0.00581 & 96
\end{tabular}

\subsubsection{Adsorption isotherms.}

From the previous result, we can express adsorption quantitatively is by deriving the adsorption isotherm that characterizes the metal/surfactant/ environment system. Various adsorption isotherms were applied to fit $\theta$ values, SMS-20-EO, SMO, and SMO-20-EO, respectively.

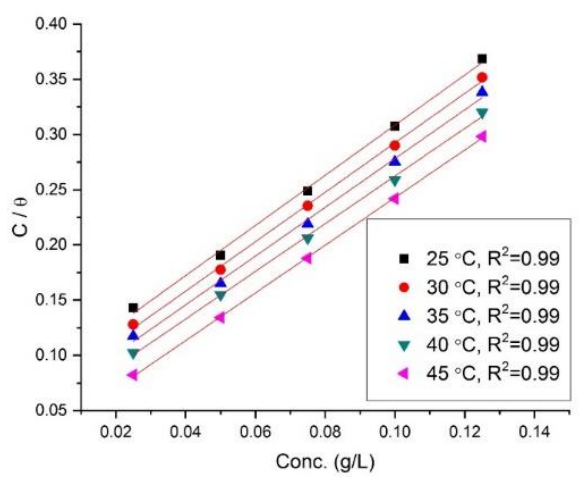

Figure 4. Langmuir adsorption isotherm plotted as $(\mathrm{C} \backslash \theta)$ vs. Conc. Of (SMO-20-EO) Surfactant for corrosion of LCS in $1 \mathrm{M} \mathrm{HCl}$ solution from WL method at $25^{\circ} \mathrm{C}$.

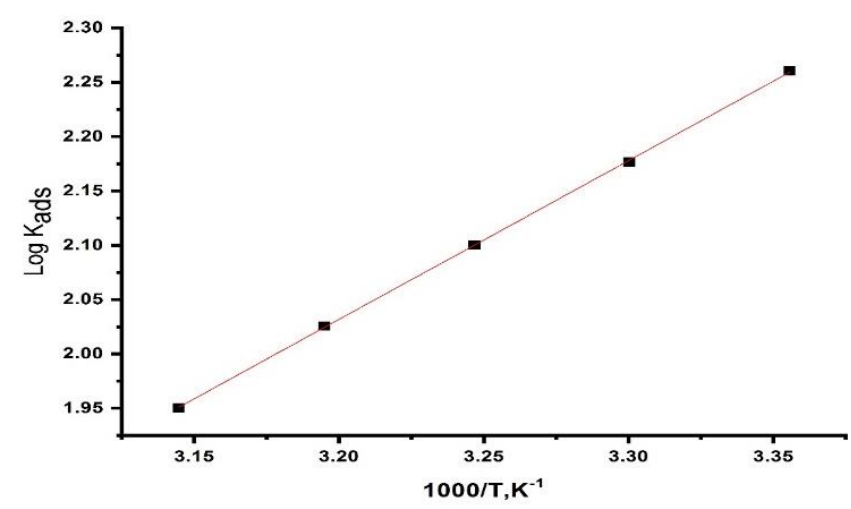

Figure 5. Variations of ( $\left.\log \mathrm{K}_{\mathrm{ads}}\right)$ vs. $(1000 \backslash \mathrm{T})$ for the adsorption of surfactant on LCS surface in $1 \mathrm{M} \mathrm{HCl}$ at different temperatures.

Langmuir adsorption isotherm is the best-fit isotherm because its regression constant is nearly unity and expressed by [33]:

$$
\mathrm{C} \backslash \theta=1 \backslash \mathrm{K}_{\mathrm{ads}}+\mathrm{C}
$$

Where $\mathrm{C}$ is the concentration (ppm) of the new surfactants in bulk electrolytes, $\mathrm{K}_{\text {ads }}$ are adsorption equilibrium constant. A plot of $\mathrm{Cl} \Theta$ versus $\mathrm{C}$ (Fig.4) at different temperatures 
should give straight lines with a slope approximately equals unity, and the $\mathrm{K}_{\text {ads }}$ equal $1 \backslash$ intercept. In order to get a comparative view, the variation of the $\left(\mathrm{K}_{\mathrm{ads}}\right)$ of the surfactants with their concentrations was calculated according to Eq. (2). The experimental data give good curves fitting for the applied adsorption isotherm as the correlation coefficients $\left(\mathrm{R}^{2}\right)$ were in the range (0.97-0.98). The values obtained are given in Table 5. The $\mathrm{K}_{\text {ads }}$ is related to the free energy of adsorption $\Delta \mathrm{G}^{\circ}$ ads as follows [34]:

$$
\left.\mathrm{K}_{\mathrm{ads}}=1 / 55.5 \exp \left[-\Delta \mathrm{G}^{\circ} \text { ads }\right] / \mathrm{RT}\right]
$$

Where 55.5 is the molar concentration of water in the solution in $\mathrm{M}^{-1}, \mathrm{R}$ is the gas constant, and $\mathrm{T}$ is the absolute temperature.

Plots of $\left(\left(\log \mathrm{K}_{\mathrm{ads}}\right)\right.$ vs. $(1000 \backslash \mathrm{T})$ Figure 5 gave the heat of adsorption $\left(\Delta \mathrm{H}^{\mathrm{o}}\right.$ ads $)$ and the standard entropy ( $\Delta \mathrm{S}^{\mathrm{o}}$ ads) according to the basic thermodynamic eq. (5)

$$
\Delta \mathrm{G}_{\text {ads }}^{\mathrm{o}}=\Delta \mathrm{H}^{\mathrm{o}} \text { ads }-\mathrm{T} \Delta \mathrm{S}_{\text {ads }}^{\mathrm{o}}
$$

Table 5 clearly showed a good dependence of $\mathrm{K}_{\text {ads }}$ on $\mathrm{T}$, indicating the good correlation among thermodynamic parameters. The negative value of $\Delta \mathrm{G}^{\mathrm{o}}$ ads refers to the spontaneity of the adsorption process and stability of the adsorbed layer on the LCS surface. Generally, values of $\Delta \mathrm{G}^{\mathrm{o}}$ ads around $-20 \mathrm{~kJ} \mathrm{~mol}^{-1}$ or lower are consistent with the physical adsorptions as electrostatic interaction between the charged atom on surfactants and the charged metal. While around $-40 \mathrm{~kJ} \mathrm{~mol}^{-1}$ or higher involve charge transfer from surfactants to the metals to form a coordinate bond (chemisorption) [35]. The values of $\Delta \mathrm{G}^{\circ}$ ads obtained were approximately equal to $-25 \pm 1 \mathrm{~kJ} \mathrm{~mol}^{-1}$, which means that the adsorption mechanism of the new surfactants on LCS in $1 \mathrm{M} \mathrm{HCl}$ involves both electrostatic adsorption and physical adsorptions [36]. The thermodynamic parameters point toward both physical adsorption as major contributors and chemisorption as minor contributors of the new surfactants onto the surface of the metal. The $\mathrm{K}_{\mathrm{ads}}$ follows the same behavior in that large values of $\mathrm{K}_{\mathrm{ads}}$ suggest good, more efficient adsorption and hence good inhibition efficiency. The values of the thermodynamic parameter for the adsorption of surfactants Table 5 can provide valuable information's about the mechanism of corrosion inhibition.

Table 5. $\left(\mathrm{K}_{\mathrm{ads}}\right),\left(\Delta \mathrm{G}^{\circ}\right.$ ads $)$ for the adsorption of surfactants on LCS in $1 \mathrm{M} \mathrm{HCl}$ from WL method at different

\begin{tabular}{|c|c|c|c|c|c|}
\hline \\
\hline Inh. & $\begin{array}{c}\text { Temp. } \\
{ }^{\circ} \mathrm{C}\end{array}$ & $\begin{array}{c}\mathbf{K}_{\text {ads }} \\
\mathbf{M}^{-1} \mathbf{x} 10^{-3} \\
\end{array}$ & $\begin{array}{c}-\Delta \mathbf{G}^{\mathbf{0}} \text { ads } \\
\mathbf{k J} \mathbf{m o l}^{-1} \\
\end{array}$ & $\begin{array}{c}-\Delta \mathbf{H}^{\mathbf{0}} \text { ads } \\
\mathbf{k J} \mathrm{mol}^{-1}\end{array}$ & $\begin{array}{c}-\Delta \mathbf{S}^{\mathbf{0}} \text { ads } \\
\mathbf{J ~ m o l}^{-1} \mathbf{K}^{-1} \\
\end{array}$ \\
\hline \multirow{5}{*}{ SMO-20-EO } & 25 & 26.73082 & 18.095 & \multirow{5}{*}{37.8151} & 187.6177 \\
\hline & 30 & 40.68348 & 19.4568 & & 189.0162 \\
\hline & 35 & 75.41478 & 21.3586 & & 192.1224 \\
\hline & 40 & 90.09009 & 22.1681 & & 191.6397 \\
\hline & 45 & 108.8139 & 23.0216 & & 187.6177 \\
\hline \multirow{7}{*}{ SMS-20-EO } & 25 & 29.19708 & 18.3137 & \multirow{4}{*}{37.8151} & 188.3515 \\
\hline & 30 & 49.38272 & 19.9451 & & 190.6276 \\
\hline & 35 & 83.26395 & 21.6122 & & 192.9457 \\
\hline & 40 & 92.3077 & 24.1418 & & 197.9452 \\
\hline & 45 & 105.344 & 25.2212 & & 198.2273 \\
\hline & 25 & 12.81723 & 16.2736 & & 181.5056 \\
\hline & 30 & 18.71608 & 17.5005 & & 182.5598 \\
\hline \multirow[t]{3}{*}{ SMO } & 35 & 32.44646 & 19.1985 & 37.8151 & 185.109 \\
\hline & 40 & 50.42864 & 20.6579 & & 186.8146 \\
\hline & 45 & 80.2543 & 16.2736 & & 181.5056 \\
\hline
\end{tabular}
temperatures.

While an endothermic adsorption process $\left(\Delta \mathrm{H}^{\mathrm{o}}\right.$ ads $\left.>0\right)$ is attributed unequivocally to chemisorption [37], an exothermic adsorption process $\left(\Delta \mathrm{H}^{\mathrm{o}}{ }_{\mathrm{ads}}<0\right)$ may involve either physical adsorption or chemical adsorption or a mixture of both processes. In the presented case, the calculated values of $\Delta \mathrm{H}^{\circ}$ ads for the adsorption of surfactants in $1 \mathrm{M} \mathrm{HCl}$, indicating that this 
surfactant may be physical adsorbed. The $\Delta \mathrm{S}^{\mathrm{o}}$ ads values in the presence of surfactants in $1 \mathrm{M}$ $\mathrm{HCl}$ are negative. This indicates that an increase in disorder takes place on going from reactants to the metal-adsorbed reaction complex [38].

\subsection{Electrochemical measurements.}

\subsubsection{Polarization (PP) measurement.}

Figure 6 shows the polarization behavior of LCS in $1 \mathrm{M} \mathrm{HCl}$ electrolyte. In the absence and presence of various concentrations of surfactants, we can see clearly that both the anodic and cathodic branches of the polarization curve exhibit a typical Tafel behavior. The corrosion rate can be determined by the Tafel extrapolation method [39]. Table 6 shows the electrochemical parameters ( $i_{\text {corr }}, E_{c o r r}, \beta_{a}, \beta_{c}$, and IE \%) associated with polarization measurements of LCS in $1 \mathrm{M} \mathrm{HCl}$ electrolytes in the absence and presence of different concentrations of surfactants.
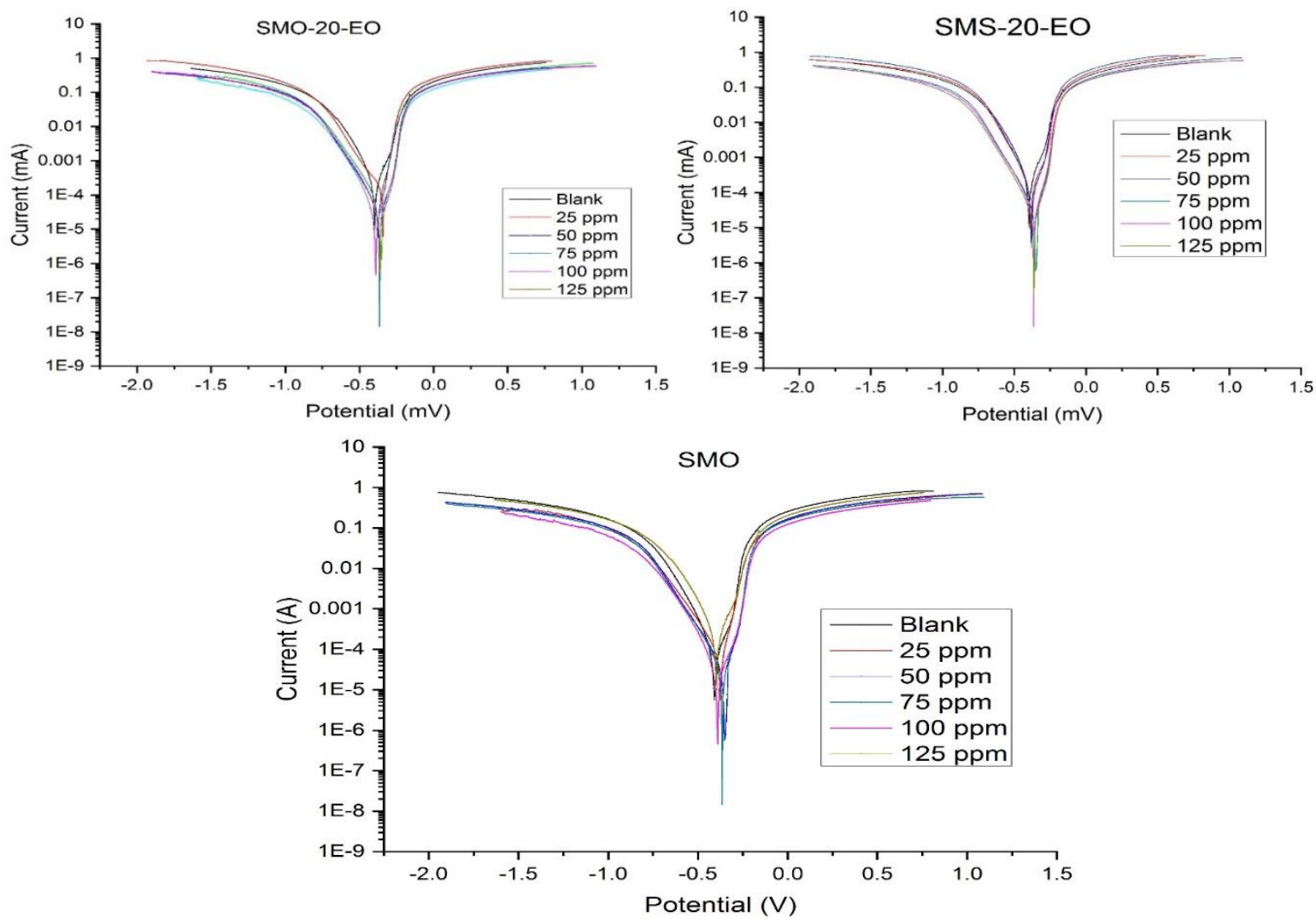

Figure 6. Polarization curve of LCS in $1 \mathrm{M} \mathrm{HCl}$ without and with different concentrations of surfactants at $25^{\circ} \mathrm{C}$.

A probe of Table 6 shows that the corrosion current (icorr) decreased, and \%IE increased with increased surfactant concentration. Also, $\beta_{\mathrm{a}}, \beta_{\mathrm{c}}$ values changed slightly with the addition of the surfactants, indicating that this surfactant functions through blocking the reaction sites on the metal surface without changing the anodic and cathodic reaction's mechanism. If the largest displacement of $\mathrm{E}_{\text {corr value surpasses }} \pm 85 \mathrm{mV}$, the inhibitor can be cathodic or anodic type inhibitor [40]. According to the $\mathrm{E}_{\text {corr }}$ values listed in Table 6, the largest $\mathrm{E}_{\text {corr }}$ shift is, which indicates that the surfactants can be classified as a mixed-type inhibitor. The values of IE\% were calculated using the following equation:

$$
\% \mathrm{IE}=\theta \times 100=\left[1-\left(\mathrm{i}_{\text {corr }} / \mathrm{i}^{\circ}{ }_{\text {corr }}\right)\right] \times 100
$$


Where $\mathrm{i}^{\circ}$ corr $=$ corrosion current density without surfactant and $\mathrm{i}_{\text {corr }}=$ corrosion current density with a surfactant, the orders of IE\% of all surfactants at a different concentration as given by polarization measurements are listed in Table 6 . The results are in good agreement with those obtained from WL measurements and order as follows: SMO-20-EO > SMS-20-EO > SMO.

Table 6. $\left(\mathrm{E}_{\text {corr }}\right),\left(\mathrm{i}_{\text {corr }}\right),\left(\beta_{\mathrm{c}}, \beta_{\mathrm{a}}\right),(\theta)$, and $(\% \mathrm{IE})$ of $\mathrm{LCS} 1 \mathrm{M} \mathrm{HCl}$ at $25^{\circ} \mathrm{C}$ for surfactants.

\begin{tabular}{|c|c|c|c|c|c|c|c|c|}
\hline Comp & Conc., ppm & $\begin{array}{c}\mathrm{i}_{\mathrm{corr}} \\
\mu \mathrm{A} \mathrm{cm}^{-2}\end{array}$ & $\begin{array}{c}- \text { Ecorr, }_{\text {co }} \\
\text { mV vs SCE }\end{array}$ & $\begin{array}{c}\beta_{\mathrm{a}} \\
\mathrm{mV} \mathrm{dec}^{-1}\end{array}$ & $\begin{array}{c}\beta_{\mathrm{c}} \\
\mathrm{mV} \operatorname{dec}^{-1}\end{array}$ & $\begin{array}{l}\text { C.R } \\
\text { mpy }\end{array}$ & $\Theta$ & $\%$ IE \\
\hline Blank & 0.0 & 351.0 & 397.0 & 117.5 & 222.2 & 160.6 & ---- & ---- \\
\hline \multirow{5}{*}{$\begin{array}{l}\text { SMO- } \\
20-E O\end{array}$} & 25 & 100.0 & 376.0 & 76.9 & 179.4 & 45.61 & 0.7151 & 71.51 \\
\hline & 50 & 91.3 & 370.0 & 75.2 & 188.4 & 41.70 & 0.7399 & 73.99 \\
\hline & 75 & 54.0 & 351.0 & 70.4 & 183.3 & 24.68 & 0.8462 & 84.62 \\
\hline & 100 & 28.5 & 345.0 & 69.9 & 146.5 & 13.03 & 0.9188 & 91.88 \\
\hline & 125 & 9.0 & 340.0 & 54.6 & 125.6 & 4.12 & 0.9744 & 97.44 \\
\hline \multirow{5}{*}{$\begin{array}{l}\text { SMS- } \\
20-E O\end{array}$} & 25 & 128.0 & 381.0 & 97.1 & 136.3 & 58.61 & 0.6353 & 63.53 \\
\hline & 50 & 86.3 & 376.0 & 73.9 & 163.6 & 39.44 & 0.7541 & 75.41 \\
\hline & 75 & 57.5 & 364.0 & 87.4 & 146.6 & 29.4 & 0.8362 & 83.62 \\
\hline & 100 & 34.5 & 365.0 & 68.2 & 141.5 & 24.1 & 0.9017 & 90.17 \\
\hline & 125 & 13.2 & 350.0 & 48.9 & 123.4 & 6.69 & 0.9624 & 96.24 \\
\hline \multirow{5}{*}{ SMO } & 25 & 130.0 & 390.0 & 99.01 & 142.0 & 62.3 & 0.6296 & 62.96 \\
\hline & 50 & 92.4 & 409.0 & 117.0 & 122.3 & 42.2 & 0.7367 & 73.67 \\
\hline & 75 & 87.3 & 376.0 & 86.2 & 172.9 & 39.9 & 0.7513 & 75.13 \\
\hline & 100 & 34.6 & 365.0 & 82.4 & 148.4 & 15.8 & 0.9014 & 90.14 \\
\hline & 125 & 25.7 & 390.0 & 104.9 & 134.3 & 11.7 & 0.9268 & 92.68 \\
\hline
\end{tabular}

3.2.2. Electrochemical impedance spectroscopy (EIS) measurements.

The impedance analysis gives us information about the properties of a surface, mechanism of actions, and kinetics of electrodes with surfactant in electrolytes as corrosive media [41]. Figure 7 contains a- Nyquist plots at open-circuit potential, all in the absence and presence of the new surfactants at $25^{\circ} \mathrm{C}$. By increasing the concentration of each surfactant lead to increase double capacitance layers and decreases $\mathrm{C}_{\mathrm{dl}}$ Values with respect to the blank (without inhibitors). Figure $7 \mathrm{a}$ enhances that. So, at certain surfactants concentration, the inhibitions efficiency following the orders: SMO-20-EO > SMS-20-EO > SMO. From the theory of EIS, the Nyquist plots don't yield perfect semicircles as expected. The deviation from the ideal semicircle was generally attributed to the frequency dispersion [42] as well as to the inhomogeneity of the surface. Surfactants inhibit corrosion primary through its adsorption on the metal surface. The point of intersection between the depressed semicircle and real axis represents $(\mathrm{Rs}+\mathrm{Rct})$ [43]. To obtain $\mathrm{C}_{\mathrm{dl}}$, the frequency (fmax) at which the imaginary component of the impedance is maximal was found. The \% IE of the inhibitor was evaluated by $R_{\mathrm{ct}}, \mathrm{C}_{\mathrm{dl}}$, and the maximum phase angle $\left(\theta_{\max }\right)$ should be $90^{\circ}$ for corrosion interface represented by a simple $\mathrm{R}-\mathrm{C}$ parallel equivalent circuit when $\mathrm{Rs}=0$. However, depressed semicircles are usually obtained for practical electrode/solution interface, which has been known to be associated with the roughness of the electrode surface. Corrosion of LCS in $1 \mathrm{M}$ $\mathrm{HCl}$ solutions increases the roughness of the electrode surface and therefore reduces the values of $\theta_{\max }$. A less depressing semicircle (with a higher maximum phase angle close to $90^{\circ}$ ) also indicates better quality of inhibitor monolayer.

EIS spectra of the investigated surfactants were analyzed using the equivalent circuit, Figure 8, which represents a single charge transfer reaction and fits well with our experimental 
results. The constant phase element, CPE, is introduced in the circuit instead of a pure doublelayer capacitor to give a more accurate fit [44]. The double-layer capacitance, $\mathrm{Cdl}_{\mathrm{dl}}$, for a circuit including a CPE parameter ( $\mathrm{Y}_{0}$ and $\left.\mathrm{n}\right)$ were calculated from eq.9 [45]:

$$
\mathrm{C}_{\mathrm{dl}}=\mathrm{Y}_{0}\left(\omega_{\max }\right)^{\mathrm{n}-1}
$$

where $Y_{0}$ is the magnitude of the $\mathrm{CPE}, \omega_{\max }=2 \pi \mathrm{f}_{\max }, \mathrm{f}_{\max }$ is the frequency at which the imaginary component of the impedance is maximal, and the factor $\mathrm{n}$ is an adjustable parameter that usually lies between 0.5 and 1.0. After analyzing the shape of the Nyquist plots, it is concluded that the curves approximated by a single capacitive semicircle, showing that the corrosion process was mainly charged-transfer controlled [46]. The general shape of the curves is very similar for all samples (in the presence or absence of surfactants at different immersion times), indicating that no change in the corrosion mechanism [47]. From the impedance data Table 7, we concluded that the value of $\mathrm{R}_{\mathrm{ct}}$ increases with increasing the concentration of the surfactants, and this indicates an increase in \% IEEIS. Which in concord with the WL and PP results obtained. In fact, the presence of surfactants enhances the value of $R_{c t}$ in acidic solution. Values of double-layer capacitance are also brought down to the maximum extent in the presence of surfactant, and the decrease in the values of CPE follows the order like that obtained for $\mathrm{i}_{\text {corr }}$ in this study. The decrease in CPE/ $\mathrm{C}_{\mathrm{dl}}$ results from a decrease in local dielectric constant and/or an increase in the thickness of the double layer, suggesting that organic derivatives inhibit the LCS corrosion by adsorption of metal/acid [48]. The \%IE was calculated from the charge transfer resistance data from eq.10 [49]:

$$
\% \mathrm{IE}_{\mathrm{EIS}}=\left[1-\left(\mathrm{R}_{\mathrm{ct}}^{\circ} / \mathrm{R}_{\mathrm{ct}}\right)\right] \times 100
$$

Where $\mathrm{R}_{\mathrm{ct}}^{\mathrm{o}}$ and $\mathrm{R}_{\mathrm{ct}}$ are the charge-transfer resistance values with and without surfactant, respectively.
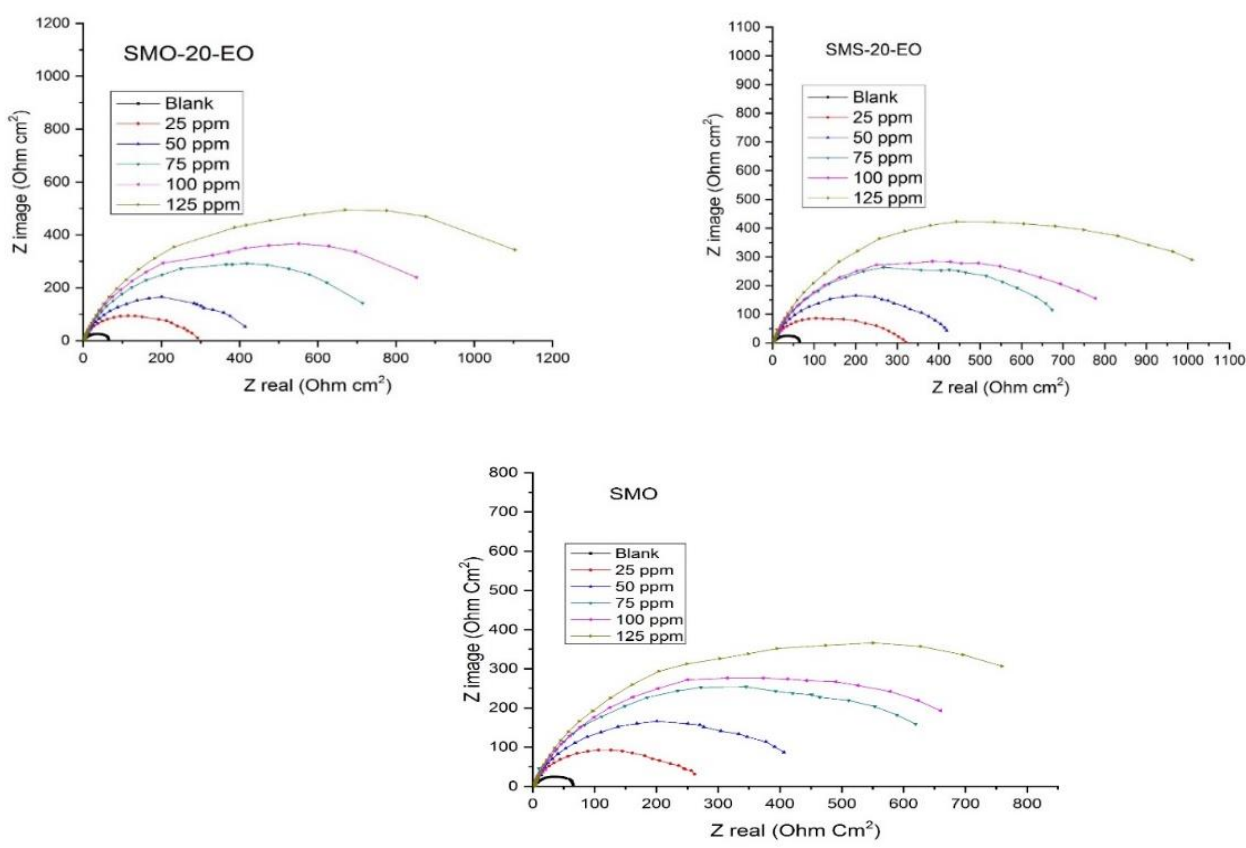

Figure 7. The Nyquist plots for the corrosion of LCS in $1 \mathrm{M} \mathrm{HCl}$ in the absence and presence of different Conc. of surfactants at $25^{\circ} \mathrm{C}$.

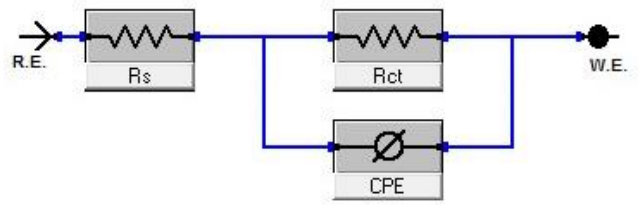

Figure 8. Equivalent circuit model used to fit experimental EIS. 
Table 7. Electrochemical kinetic parameters were obtained by the EIS technique for in $1 \mathrm{M} \mathrm{HCl}$ without and with various concentrations of surfactants at $25^{\circ} \mathrm{C}$.

\begin{tabular}{l|c|c|c|c|c}
\multirow{2}{*}{ Comp } & $\begin{array}{c}\text { Conc., } \\
\mathrm{ppm}\end{array}$ & $\begin{array}{c}\mathrm{R}_{\mathrm{ct}}, \\
\Omega \mathrm{cm}^{2}\end{array}$ & $\begin{array}{c}\mathrm{C}_{\mathrm{dl}}, \\
\mathrm{x} 10^{-4} \mathrm{Fcm}^{-2}\end{array}$ & $\theta$ & $\% \mathrm{IE}$ \\
\hline Blank & 0 & 65.88 & 2.41 & -- & -- \\
\hline \multirow{2}{*}{ SMO-20-EO } & 25 & 395.6 & 1.32 & 0.833 & 83.3 \\
\hline & 50 & 649.7 & 1.27 & 0.898 & 89.8 \\
\hline & 75 & 711.3 & 1.26 & 0.907 & 90.7 \\
\hline & 100 & 914.5 & 1.11 & 0.928 & 92.8 \\
\hline SMS-20-EO & 125 & 1228 & 0.99 & 0.946 & 94.6 \\
\hline & 25 & 194.7 & 1.42 & 0.662 & 66.2 \\
\hline & 50 & 362.3 & 1.25 & 0.818 & 81.8 \\
\hline & 75 & 616.6 & 1.13 & 0.893 & 89.3 \\
\hline SMO & 100 & 709.9 & 1.09 & 0.907 & 90.7 \\
\hline & 125 & 1161 & 0.92 & 0.943 & 93.3 \\
\hline & 25 & 212.0 & 1.24 & 0.689 & 68.9 \\
\hline & 50 & 355.5 & 1.19 & 0.815 & 81.5 \\
\hline & 75 & 612.7 & 1.12 & 0.892 & 89.2 \\
\hline
\end{tabular}

3.2.2. Electrochemical frequency modulation (EFM) measurements.

EFM is a nondestructive corrosion measurement technique that can directly and quickly determine the corrosion current values without prior knowledge of Tafel slopes and with only a small polarizing signal. These advantages of the EFM technique make it an ideal candidate for online corrosion monitoring [50]. The great strength of the EFM is the causality factors, which serve as an internal check on the validity of EFM measurement. The causality factors CF-2 and CF-3 are calculated from the frequency spectrum of the current responses. Figure 9 shows the EFM intermodulation spectra (current vs. frequency) of LCS in $\mathrm{HCl}$ solution containing different concentrations of surfactants. The larger peaks were used to calculate the corrosion current density ( $\left.\mathrm{i}_{\text {corr }}\right)$, the Tafel slopes $\left(\beta_{\mathrm{c}}\right.$ and $\beta_{\mathrm{a}}$ ), and the causality factors $(\mathrm{CF}-2$ and CF-3). These electrochemical parameters were listed in Table 8.

Table 8. Electrochemical kinetic parameters were obtained from the EFM technique for LCS in $1 \mathrm{M} \mathrm{HCl}$ in the absence and presence of different concentrations of surfactants.

\begin{tabular}{|c|c|c|c|c|c|c|c|c|c|}
\hline \multirow[b]{2}{*}{ Comp } & & & & & & & & & \\
\hline & $\begin{array}{l}\text { Conc., } \\
\text { ppm }\end{array}$ & $\begin{array}{l}\mathrm{i}_{\text {corr }} \\
\mu \mathrm{Acm}^{-2}\end{array}$ & $\begin{array}{l}\beta_{\mathrm{c}} \\
\mathrm{mVdec} \\
-1\end{array}$ & $\begin{array}{l}\beta_{\mathrm{a}}, \\
\mathrm{mVdec}^{-1}\end{array}$ & $\begin{array}{l}\text { C.R , } \\
\text { mpy }\end{array}$ & CF-2 & CF-3 & $\theta$ & $\% \mathrm{IE}$ \\
\hline \multirow[t]{3}{*}{ Blank } & 0.0 & 408 & 124.5 & 196.9 & 168.4 & 2.03 & 2.95 & -- & -- \\
\hline & 25 & 29.5 & 87.3 & 99.85 & 13.49 & 1.855 & 3.54 & 0.927 & 92.77 \\
\hline & 50 & & & & & & & & \\
\hline \multirow[t]{5}{*}{$\begin{array}{l}\text { SMO-20- } \\
\text { EO }\end{array}$} & 5 & 17.1 & 29.5 & 30.85 & 9.9 & 1.92 & 7.05 & 0.962 & 95.3 \\
\hline & 75 & 13.6 & 44.9 & 48.98 & 7.25 & 1.53 & 3.06 & 0.966 & 96.7 \\
\hline & 100 & 12.3 & 64.6 & 69.30 & 6.51 & 1.433 & 1.43 & 0.970 & 97.0 \\
\hline & 125 & 11.0 & 47.9 & 52.44 & 5.45 & 1.00 & 3.92 & 0.973 & 97.5 \\
\hline & 25 & 95.2 & 86.3 & 109.5 & 43.5 & 1.91 & 2.99 & 0.766 & 76.6 \\
\hline \multirow{5}{*}{$\begin{array}{l}\text { SMS-20- } \\
\text { EO }\end{array}$} & 50 & 35.1 & 97.3 & 103.5 & 33.5 & 1.85 & 3.54 & 0.914 & 91.4 \\
\hline & 75 & 25.5 & 54.9 & 38.08 & 15.3 & 1.53 & 3.06 & 0.937 & 93.7 \\
\hline & 100 & 16.9 & 39.5 & 39.85 & 7.90 & 1.92 & 3.06 & 0.952 & 95.8 \\
\hline & 125 & 14.3 & 69.5 & 83.50 & 6.52 & 1.00 & 1.73 & 0.964 & 96.5 \\
\hline & 25 & 85.0 & 93.5 & 103.8 & 38.8 & 1.00 & 3.05 & 0.791 & 79.1 \\
\hline \multirow[t]{4}{*}{ SMO } & 50 & 35.1 & 29.5 & 30.85 & 26.9 & 1.92 & 3.00 & 0.913 & 91.3 \\
\hline & 75 & 29.5 & 87.3 & 99.85 & 18.5 & 1.85 & 3.54 & 0.927 & 92.7 \\
\hline & 100 & 23.6 & 74.9 & 58.98 & 11.2 & 1.53 & 3.06 & 0.942 & 94.2 \\
\hline & 125 & 20.1 & 37.9 & 59.44 & 7.45 & 1.00 & 3.91 & 0.950 & 95.0 \\
\hline
\end{tabular}




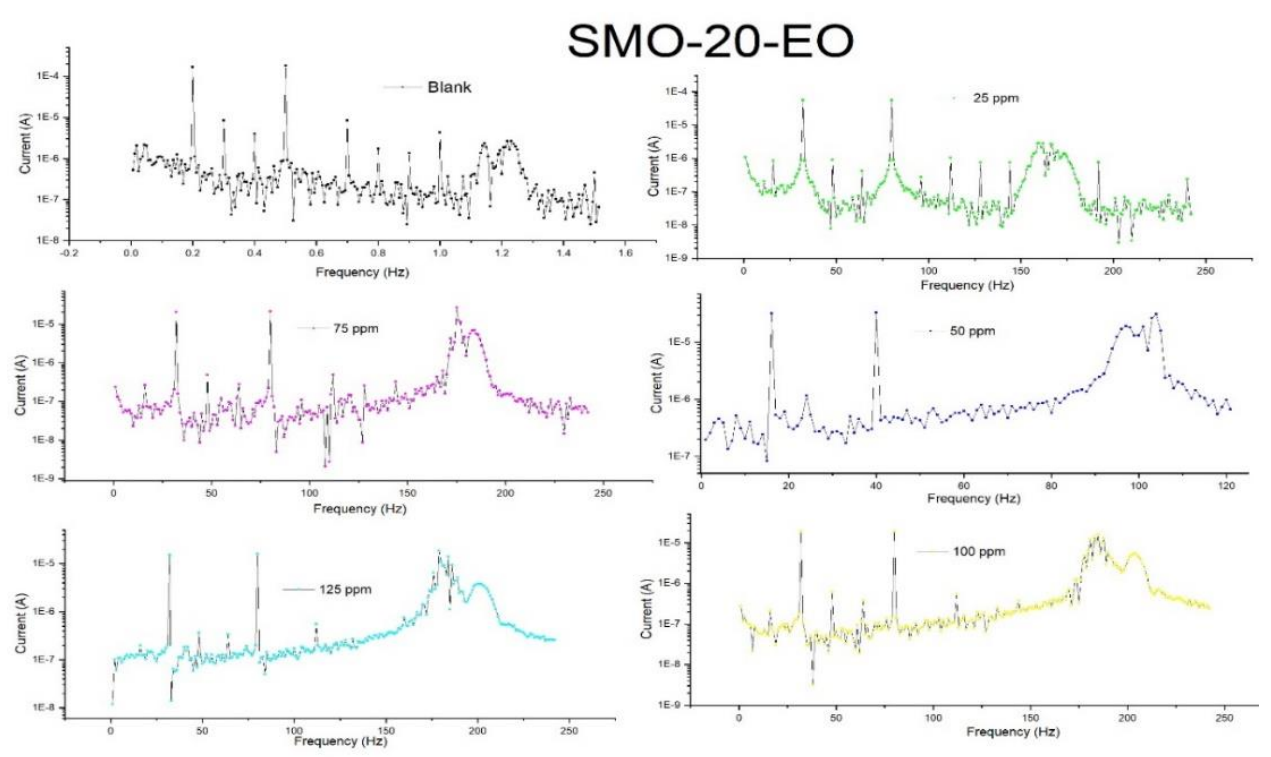

\section{SMS-20-EO}
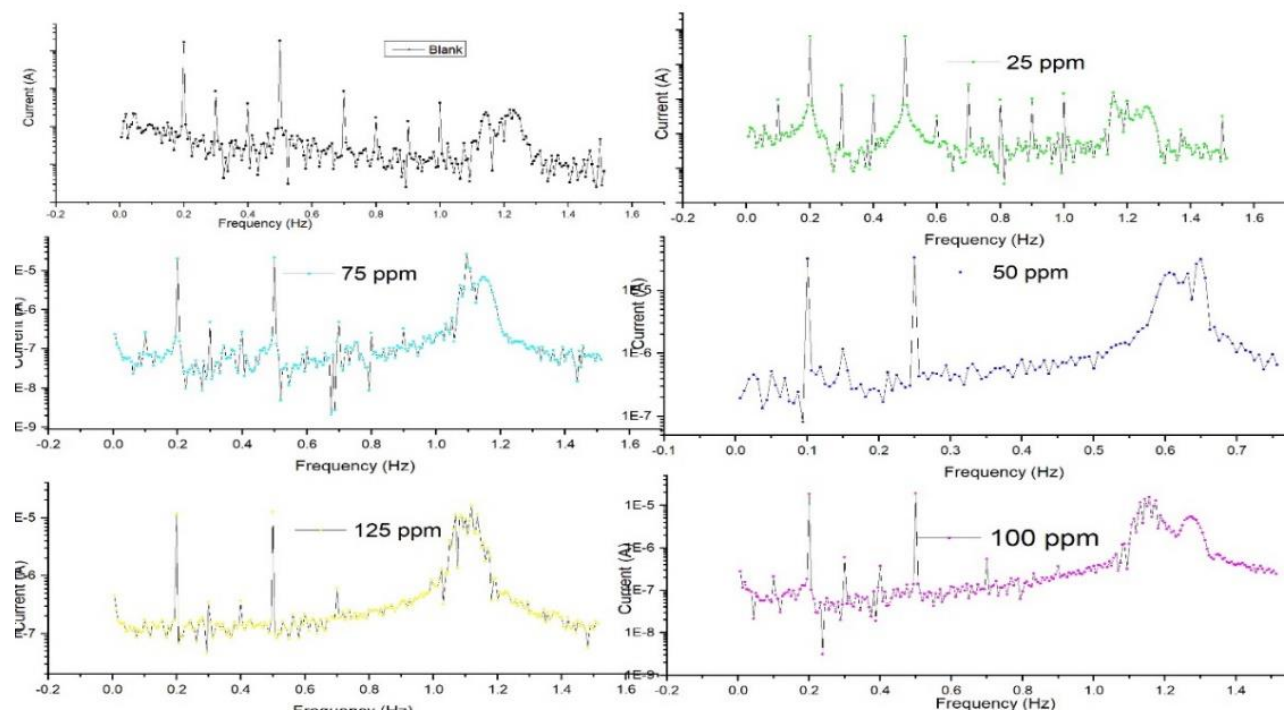

SMO

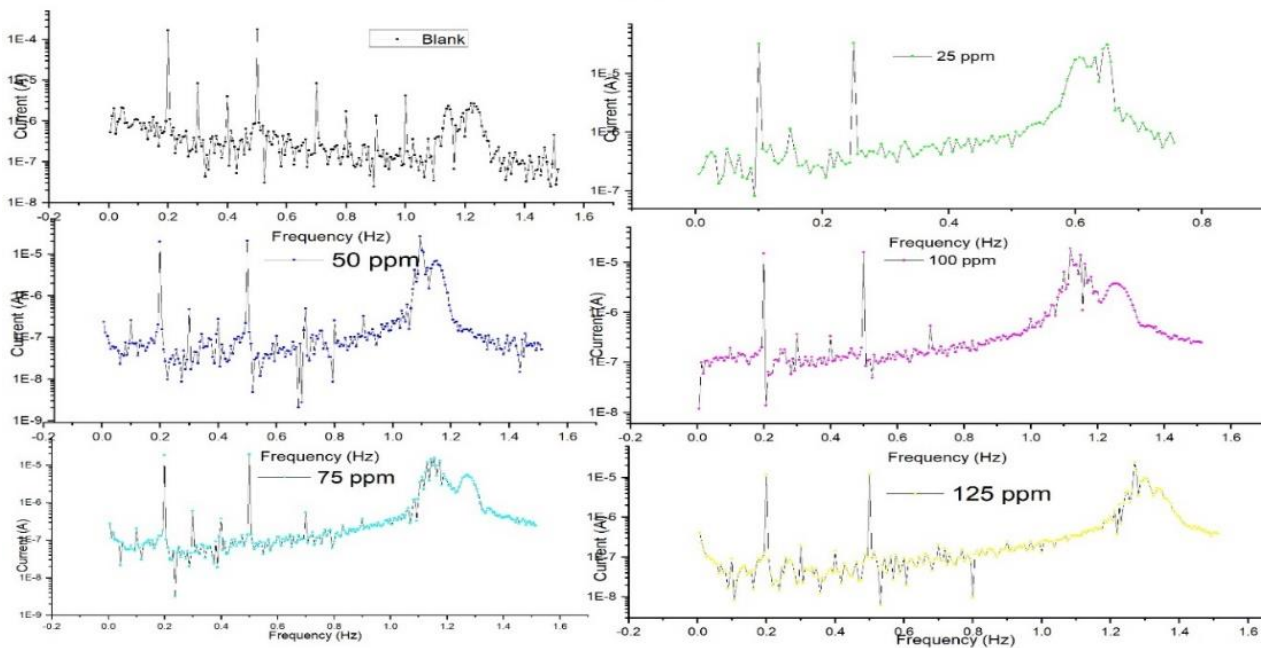

Figure 9. EFM spectra of LCS in $1 \mathrm{M} \mathrm{HCl}$ in the absence and presence of different Conc. of surfactants at $25^{\circ} \mathrm{C}$.

The data presented in Table 8, obviously showed that the addition of any one of the tested compounds at a given concentration to the acidic solution decreases the corrosion current 
density, indicating that these surfactants inhibit the corrosion of LCS in $1 \mathrm{M} \mathrm{HCl}$ through adsorption. The causality factors obtained under different experimental conditions are approximately equal to the theoretical values ( 2 and 3 ), indicating that the measured data are verified and of good quality. The \% IEEFM increases by increasing the surfactant concentrations and was calculated as in Eq. (8). The IE obtained from this method is in the order: SMO-20EO $>$ SMS-20-EO > SMO.

\subsection{Surface examinations.}

\subsubsection{Scanning electron microscopy (SEM) analysis.}

As shown in Fig.10a SEM for the LCS surface shows the LCS surface image in the air without an explosion in any media. Fig. 10b-e Shows surface destroy of the LCS after immersion in the corrosive media in the absence and presence of the surfactant for $24 \mathrm{hrs}$. In the absence of the surfactant, the results exhibited that a thick porous layer of corrosion product (oxide film) covers the entire metal surface; the surface was strongly damaged, so the surface of the metal cannot be seen. While Fig. 10c-e presents the image of the electrode surface in the presence of $125 \mathrm{ppm}$ of surfactants (SMO-20-EO > SMS-20-EO > SMO). The images of Fig.10c,e showed that the surface is almost free from damages, and it is smooth, this indicates the presence of a good protective film present on the LCS surface, also confirms the highest IE\% of the investigated new ethoxylated surfactants.

\subsection{Mechanism of surfactant inhibition.}

In the present work, the mechanism of corrosion inhibitions have a complex process that begins with the formation of a monolayer as a protective layer on the surface of the metal. This protective layer depends on many factors such as the concentration of surfactant inhibitor, temperature, and nature of the corresponding surface, the interaction between surfactant inhibitor and substrate, and chemical reactions. The adsorption of a surfactant molecule on the surface of a metal in the corrosive media is the first state on the mechanism actions. This protective process is influenced by the surface charge of the metal, the chemical composition of surfactant inhibitors, and types of corrosive electrolytes. The following equation illustrates the adsorption reaction occurs on the metal surface by surfactant molecules.

$$
\text { Surfactant }_{\text {sol. }}+\mathrm{nH}_{2} \mathrm{O}_{\text {ads }}=\text { Surfactant }_{\text {ads. }}+\mathrm{nH}_{2} \mathrm{O}_{\text {Sol }} \text {. }
$$

While $\mathrm{n}$ is the number of water molecules replaced by the surfactant molecules adsorbed on the metal surface, it's clear that the amount of (n) is related to the surfactant inhibitor size respected with the water molecules. The keyword of surfactant inhibition was its functions group adsorbed on the metal surface. So, the corrosion inhibition is related to the adsorption ability of the surfactant molecule on the surface of the metal, which is directly related to the capacity of a surfactant molecule to aggregate to form micelles. The critical micelle concentration $\mathrm{CMC}$ is the main factor in determining the effectiveness of the corrosion inhibitor. Under CMC, by increasing the surfactant concentration, the molecules tend to aggregate at the interface, and this interfacial aggregation reducing the surface tension. Above $\mathrm{CMC}$, the metal surface was completely covered with a monolayer by surfactant molecules. The corrosion rate (C.R.) increases with increasing the immersion time. This leads to the dissolution of the iron as the component of the main item of LCS to form an oxide film as a corrosion product, which reduces the corrosion by the time [51]. The influence on increase 
temperature of electrolytes leads to increase corrosion rate due to the desorption of surfactant molecules from metals surface.

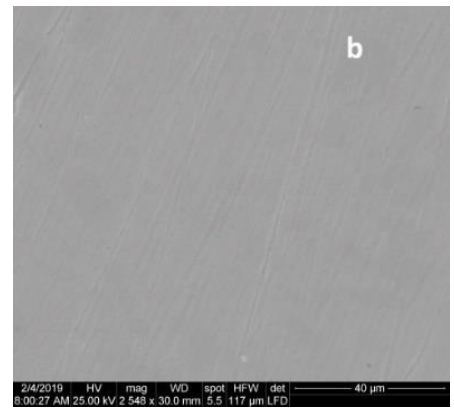

Free (a)

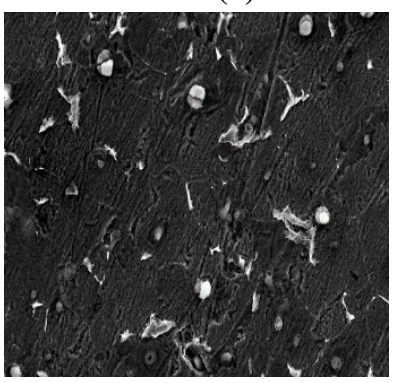

SMO-20-EO (c)

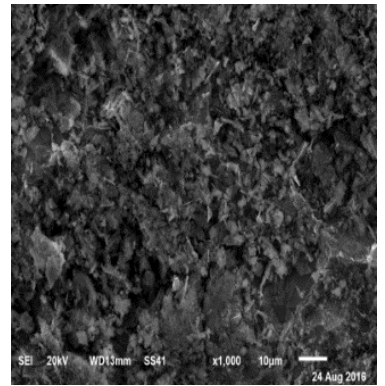

Blank (b)

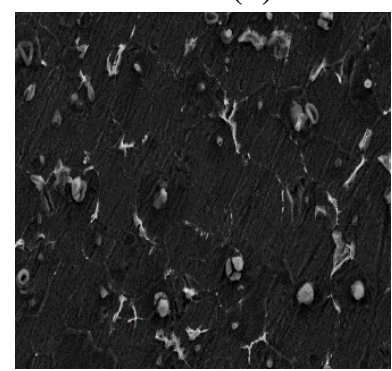

SMS-20-EO (d)

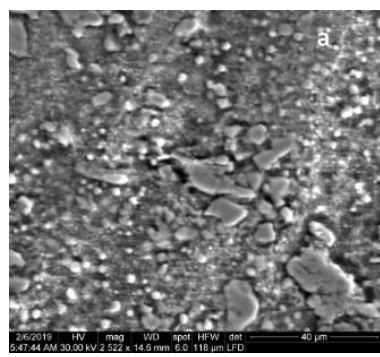

SMO (e)

Figure 10. (a-e) Scanning Electron Microscope graphs of LCSsurface. a) Before immersion in $1 \mathrm{M} \mathrm{HCl,} \mathrm{b)} \mathrm{after}$ $24 \mathrm{hrs}$. Of immersion in $1 \mathrm{M} \mathrm{HCl}$ and c) after $24 \mathrm{hrs}$. Of immersion in $1 \mathrm{M} \mathrm{HCl}+125 \mathrm{ppm}$ of surfactant (SMO20-EO) and d) after $24 \mathrm{hrs}$. Of immersion in $1 \mathrm{M} \mathrm{HCl}+125 \mathrm{ppm}$ of surfactant (SMS-20-EO), e) after $24 \mathrm{hrs}$. Of immersion in $1 \mathrm{M} \mathrm{HCl}+125 \mathrm{ppm}$ of surfactant $(\mathrm{SMO})$ at $25^{\circ} \mathrm{C}$.

\section{Conclusions}

The new ethoxylated surfactant has good applications as green corrosion inhibitors.

IE \% inhibitions the efficiency of the new ethoxylated surfactant increase by increasing its concentration. Until reaching Maximum value at (CMC). The IE\% depends on the temperature, the concentration of new surfactant inhibitors, and its chemical structure, which appear obviously in the following order according to IE\% is: SMO-20-EO > SMS-20-EO > SMO. While The IE \% increases as the length of the hydrocarbon chain are increased, and the unsaturated double bond increase. The current new ethoxylated surfactant is mixed type corrosion inhibitors in $\mathrm{HCl}$ electrolytes due to its inhibition action on both the anodic process of metal dissolution and the cathodic process of hydrogen evolution. By adding the surfactant leads to a decrease in the double layer capacitance with respect to the blank due to the formation of barriers films by adsorptions phenomenon, which leads to raising IE\%. The adsorption of new non-ionic surfactants on LCS in $\mathrm{HCl}$ electrolytes obey Langmuir adsorption isotherm. The percentage of IE\% of surfactants obtained from the Weight loss, Polarization, E-Impedance, and E-Frequency Modulation techniques are in good agreement. 


\section{Funding}

This research received no external funding.

\section{Acknowledgments}

The authors are grateful to Prof. Osama Abo-Zaid, Sultan Qaboos University, Faculty of Science, Chemistry Department, Muscat, Oman. For his continuous support and also indebted to Mr. Ahmed Hussain, Al-Mustansiriyah University, Chemistry Department, Iraq. For his effort in the ${ }^{1} \mathrm{H}-\mathrm{NMR}$ technique.

\section{Conflicts of Interest}

The authors declare that they have no conflict of interest.

\section{References}

1. Sliem, M.H.; Afifi, M.; Radwan, A.B.; Fayyad, E.M.; Shibl, M.F.; Heakal, F.E.T.; Abdullah, A.M. AEO7 surfactant as an eco-friendly corrosion inhibitor for LCS in $\mathrm{HCl}$ solution. Nature Scientific reports 2019, 9, 1-16, https://doi.org/10.1038/s41598-018-37254-7.

2. Frignani, A.; Grassi, V.; Zanotto, F.; Zucchi, F. Inhibition of AZ31 Mg alloy corrosion by anionic surfactants. Corrosion science 2012, 63, 29-39, https://doi.org/10.1016/j.corsci.2012.05.012.

3. Badawi, A.M.; Hegazy, M.A.; El-Sawy, A.A.; Ahmed, H.M.; Kamel, W.M. Novel quaternary ammonium hydroxide cationic surfactants as corrosion inhibitors for carbon steel and as biocides for sulfate reducing bacteria (SRB). Materials Chemistry and Physics 2010, 124, 458-465, https://doi.org/10.1016/j.matchemphys.2010.06.066.

4. Wang, X.; Yang, H.; Wang, F. A cationic gemini-surfactant as effective inhibitor for mild steel in $\mathrm{HCl}$ solutions. Corrosion Science 2010, 52, 1268-1276, https://doi.org/10.1016/j.corsci.2009.12.018.

5. Labena, A.; Hegazy, M.A.; Sami, R.M.; Hozzein, W.N. Multiple applications of a novel cationic gemini surfactant: Anti-microbial, anti-biofilm, biocide, salinity corrosion inhibitor, and biofilm dispersion (Part II). Molecules 2020, 25, https://doi.org/10.3390/molecules25061348.

6. Shaban, M.M.; Eid, A.M.; Farag, R.K.; Negm, N.A.; Fadda, A.A.; Migahed, M.A. Novel trimeric cationic pyrdinium surfactants as bi-functional corrosion inhibitors and antiscalants for API 5L X70 LCS against oilfield formation water. Journal of Molecular Liquids 2020, 305, https://doi.org/10.1016/j.molliq.2020.112817.

7. Wang, W.; Free, M.L. Prediction and measurement of corrosion inhibition of mild steel using non-ionic surfactants in chloride media. Corrosion science 2004, 46, 2601-2611, https://doi.org/10.1016/s0010938x(03)00152-5.

8. Abd El-Ghaffar, M.A.; Sherif, M.H.; El-Habab, A.T. Synthesis, characterization, and evaluation of ethoxylated lauryl-myrisityl alcohol non-ionic surfactants as wetting agents, anti-foamers, and minimum film forming temperature reducers in emulsion polymer lattices. Journal of Surfactants and Detergents 2017, 20, 117-128, https://doi.org/10.1007/s11743-016-1898-4.

9. Zhu, Y.; Free, M.L.; Woollam, R.; Durnie, W. A review of surfactants as corrosion inhibitors and associated modeling. Progress in Materials Science 2017, 90, 159-223, https://doi.org/10.1016/j.pmatsci.2017.07.006.

10. Fouda, A.S.; Etaiw, S.H.; El-Habab, A.T.; Wahba, A.M. Synthesis, Characterization, and Application of New Nonionic Surfactant as a Corrosion Inhibitor for Carbon Steel in $1 \mathrm{M}$ Hydrochloric Acid Solution. Journal of Bio-and Tribo-Corrosion 2020, 6, 1-9, https://doi.org/10.1007/s40735-020-00373-8.

11. El-Katori, E.E.; Al Angari, Y.M. Electrochemical and theoretical evaluation on the corrosion inhibition of carbon steel by organic selenides in acidic medium. Int. J. Electrochem. Sci 2018, 13, 4319-4337, https://doi.org/10.20964/2018.05.05.

12. Paramasivam, S.; Kulanthai, K.; Sadhasivam, G.; Subramani, R. Corrosion Inhibition of Mild Steel in Hydrochloric Acid using4-(pyridin-2yl)-Np-tolylpiperazine-1-carboxamide. Int. J. Electrochem. Sci 2016, 11, 3393-3414, https://doi.org/10.20964/10109.

13. Al-Sabagh, A.M.; El Basiony, N.M.; Sadeek, S.A.; Migahed, M.A. Scale and corrosion inhibition performance of the newly synthesized anionic surfactant in desalination plants: experimental, and theoretical investigations. Desalination 2018, 437, 45-58, https://doi.org/10.1016/j.desal.2018.01.036.

14. Deyab, M.A. Efficiency of cationic surfactant as microbial corrosion inhibitor for carbon steel in oilfield saline water. Journal of Molecular Liquids 2018, 255, 550-555, https://doi.org/10.1016/j.molliq.2018.02.019. 
15. El-Hajjaji, F.; Belghiti, M.E.; Hammouti, B.; Jodeh, S.; Hamed, O.; Lgaz, H.; Salghi, R. Adsorption and corrosion inhibition effect of 2-mercaptobenzimidazole (surfactant) on a carbon steel surface in an acidic medium: experimental and monte carlo simulations. Portugaliae Electrochimica Acta 2018, 36, 197-212, https://doi.org/10.4152/pea.201803197.

16. Hegazy, M.A.; Abdallah, M.; Alfakeer, M.; Ahmed, H. Corrosion inhibition performance of a novel cationic surfactant for protection of carbon steel pipeline in acidic media. Int. J. Electrochem. Sci. 2018, 13, 68246842, https://doi.org/10.20964/2018.07.53.

17. Pakiet, M.; Kowalczyk, I.; Garcia, R. L.; Moorcroft, R.; Nichol, T.; Smith, T. Brycki, B. Gemini surfactant as multifunctional corrosion and biocorrosion inhibitors for mild steel. Bio-electrochemistry 2019, 128, 252262, https://doi.org/10.1016/j.bioelechem.2019.04.005.

18. Saleh, M.M.; Mahmoud, M.G.; Abd El-Lateef, H.M. Comparative study of synergistic inhibition of mild steel and pure iron by 1-hexadecylpyridinium chloride and bromide ions. Corrosion Science 2019, 154, 7079, https://doi.org/10.1016/j.corsci.2019.03.048.

19. Abdallah, M.; Al-abdali, F.H.; Kamar, E.M.; El-Sayed, R.; Hameed, R.A. Corrosion inhibition of aluminum in $1.0 \mathrm{M} \mathrm{HCl}$ solution by some non-ionic surfactant compounds containing five membered heterocyclic moiety. Chemical Data Collections 2020, 28, https://doi.org/10.1016/j.cdc.2020.100407.

20. Hameed, R.S.A.; Al-Bagawi, A.H.; Shehata, H.A.; Shamroukh, A.H.; Abdallah, M. Corrosion Inhibition and Adsorption Properties of Some Heterocyclic Derivatives on C-Steel Surface in HCl. Journal of Bio-and Tribo-Corrosion 2020, 6, 1-11, https://doi.org/10.1007/s40735-020-00345-y.

21. Ayukayeva, V.N.; Boiko, G.I.; Lyubchenko, N.P.; Sarmurzina, R.G.; Mukhamedova, R.F.; Karabalin, U.S.; Dergunov, S.A. Polyoxyethylene sorbitan trioleate surfactant as an effective corrosion inhibitor for carbon steel protection. Colloids and Surfaces A: Physicochemical and Engineering Aspects 2019, 579, https://doi.org/10.1016/j.colsurfa.2019.123636.

22. Hoydonckx H.E.; De Vos D.E.; Chavan S.A.; Jacobs P.A. Esterification and transesterification of renewable chemicals. Top. Catal. 2004, 27, 83-96, https://doi.org/10.1023/b:toca.0000013543.96438.1a.

23. Stockburger, G.J. Process for preparing sorbitan esters. Patent \# US 4297290, 1981.

24. Ellis, J.M.H.; Lewis, J.J.; Beattie, J. Manufacture of fatty acid esters of sorbitan as surfactants. Patent \# US 6362353, 2002.23.

25. Milstein, N. Improved esterifi - cation of oxyhydrocarbon polyols and ethers thereof, and products therefrom. Patent \# WO 9200947, 1992.

26. Smidrkal, J.; Cervenkova, R.; Filip, V. Two-stage synthesis of sorbitan esters, and physical properties of the products. Eur. J. Lipid Sci. Technol. 2004, 106, 851-855, https://doi.org/10.1002/ejlt.200401003.

27. Farag, A.A.; Badr, E.A. Non-ionic surfactant loaded on gel capsules to protect downhole tubes from produced water in acidizing oil wells. Corrosion Reviews 2020,38, 151-164, https://doi.org/10.1515/corrrev2019-0030.

28. Heakal, F.E.; Elkholy, A.E. Gemini surfactants as corrosion surfactants for LCS. J Mol Liq 2017, 230, 395407..

29. Abd El-Lateef, H.M.; Abo-Riya, M.A.; Tantawy, A.H. Empirical and quantum chemical studies on the corrosion inhibition performance of some novel synthesized cationic gemini surfactants on LCS pipelines in acid pickling processes. Corros Sci. 2016, 108, 94-110, https://doi.org/10.1016/j.corsci.2016.03.004.

30. Abd El-Lateef, H.M.; Tantawy, A.H.; Abdel-Hamid, A.A. Novel quaternary ammonium-based cationic surfactants: synthesis, surface activity and evaluation as corrosion surfactants for C1018 LCS in acidic chloride solution. J Surfact Deterg 2016, 20, 735-753, https://doi.org/10.1007/s11743-017-1947-7.

31. Yin, C.; Kong, M.; Zhang, J.; Wang, Y.; Ma, Q.; Chen, Q.; Liu, H. Influence of Hydroxyl Groups on the Inhibitive Corrosion of Gemini Surfactant for LCS. ACS omega 2020, 5, 2620-2629, https://doi.org/10.1021/acsomega.9b02989.

32. Bedaira, M.A.; El-Sabbah, M.M.B.; Fouda, A.S.; Elaryian, H.M. Synthesis, electrochemical and quantum chemical studies of some prepared surfactants based on azodye and Schiff base as corrosion surfactants for steel in acid medium. Corros Sci. 2017, 128, 54-72, https://doi.org/10.1016/j.corsci.2017.09.016.

33. Adewuyi, A.; Göpfert, A.; Wolff, T. Succinyl amide gemini surfactant from Adenopus breviflorus seed oil: A potential corrosion surfactant of mild steel in acidic medium. J Ind Crop 2014, 52, 439-449, https://doi.org/10.1016/j.indcrop.2013.10.045.

34. Abd-Elaal, A.A.; Shaban, S.M. Tawfik, S.M. Three Gemini cationic surfactants based on polyethylene glycol as effective corrosion surfactant for mild steel in acidic environment. $J$ The Association of Arab Universities for Basic and Applied Sciences 2017, 24, 54-65, https://doi.org/10.1016/j.jaubas.2017.03.004.

35. Al-Sabagh, A.M.; Nasser, N.M.; Khamis, E.A.; Mahmoud, T. Synthesis of non-ionic surfactants based on alkylene diamine and evaluation of their corrosion inhibition efficiency on LCS in formation water. Egypt $J$ Petrol. 2017, 26, 41-51, https://doi.org/10.1016/j.ejpe.2016.03.001.

36. Negm, N.A.; Al-Sabagh, A.M.; Migahed, M.A.; Abdel Bary, H.M.; El Din, H.M. Effectiveness of some diquaternary ammonium surfactants as corrosion surfactants for LCS in $0.5 \mathrm{M} \mathrm{HCl}$ solution. Corros Sci. 2010, 52, 2122-2132, https://doi.org/10.1016/j.corsci.2010.02.044. 
37. Migahed, M.A. Abd-El-Raouf, M. Al-Sabagh, A.M. Abd-El-Bary, H.M. Effectiveness of some non-ionic surfactants as corrosion surfactants for LCS pipelines in oil fields. Electrochim Acta 2005, 50, 4638-4689, https://doi.org/10.1016/j.electacta.2005.02.021.

38. Aiad, I.; El-Sukkary, M.M.; Soliman, E.A.; El-Awady, M.Y.; Shaban, S.M. Inhibition of mild steel corrosion in acidic medium by some cationic surfactants. $J$ Ind Eng Chem 2014, 20, 3524-3535, https://doi.org/10.1016/j.jiec.2013.12.045.

39. Kousar, K.; Ljungdahl, T.; Wetzel, A.; Dowhyj, M.; Oskarsson, H.; Walton, A.S.; Lindsay, R. An Exemplar Imidazoline Surfactant for Corrosion Inhibitor Studies: Synthesis, Characterization, and Physicochemical Properties. Journal of Surfactants and Detergents 2020, 23, 225-234. https://doi.org/10.1002/jsde.12363.

40. Shalabi, M.N.; Osman, M.M. Protection of copper surface against corrosion by cationic surfactant in seawater. J Disp Sci Tech. 2009, 30, 677-683, https://doi.org/10.1080/01932690802598986.

41. Reichenbacher, M.; Popp, J. Chapter 2-Vibrational Spectroscopy. In: Challenges in molecular structure determination. Berlin Heidelberg, Springer-Verlag 2012.

42. Fuchs-Godec, R. Effects of surfactants and their mixtures on inhibition of the corrosion process of ferritic stainless steel. Electrochim Acta 2009, 54, 2171-2179, https://doi.org/10.1016/j.electacta.2008.10.014.

43. Frignani, A.; Grassi, V.; Zanotto, F.; Zucchi, F. Inhibition of AZ31 Mg alloy corrosion by anionic surfactants. Corros Sci 2012, 63, 29-39, https://doi.org/10.1016/j.corsci.2012.05.012.

44. Elbatouti, M.; Fetouh, H.A. Extraction of eco-friendly and biodegradable surfactant for inhibition of copper corrosion during acid pickling. Adsorption Science-Technology 2019, 37, 649-663, https://doi.org/10.1177/0263617419865130.

45. Abd El Rehim, S.S.; Hassan, H.H.; Amin, M.A. The corrosion inhibition study of sodium dodecyl benzene sulphonate to aluminium and its alloys in $1.0 \mathrm{M} \mathrm{HCl}$ solution. Materials Chemistry and Physics 2003, 78, 337-348, https://doi.org/10.1016/S0254-0584(01)00602-2.

46. Atia, A.A.; Saleh, M.M. Inhibition of acid corrosion of steel in cetylpyridinium chloride. J. Appl. Electrochem 2003, 33, 171-177, https://doi.org/10.1023/a:1024083117949.

47. Branzoi, V.; Golgovici, F.; Branzoi, F.Aluminum corrosion in hydrochloric acid solutions and effect of some organic inhibitors. Mater. Chem. Phys. 2002, 78, 122-131, https://doi.org/10.1016/S0254-0584(02)00222-5.

48. Ramji, K.; Cairns, D.R.; Rajeswari, S. Synergistic inhibition effect of 2-mercaptobenzothiazole and Tween80 on the corrosion of brass in $\mathrm{NaCl}$ solution. Appl. Surf. Sci. 2008, 254, 4483-4493, https://doi.org/10.1016/j.apsusc.2008.01.031.

49. Tozar, A.; Karahan, İ.H. Effect of octylphenyl ether group non-ionic surfactant on the electrodepositon of the hexagonal boron nitride reinforced Ni-B matrix composite coatings. Surface and Coatings Technology 2020, 381, https://doi.org/10.1016/j.surfcoat.2019.125131.

50. Fouda, A.S.; Al-Zehry, H.H.; Elsayed, M. Synergistic Effect of Potassium Iodide with Cassia italica Extract on the Corrosion Inhibition of LCS Used in Cooling Water Systems in 0.5 M H2SO4. Journal of Bio- and Tribo-Corrosion 2018, 4, https://doi.org/10.1007/s40735-018-0138-z.

51. Han, T.; Guo, J.; Zhao, Q.; Wu, Y.; Zhang, Y. Enhanced corrosion inhibition of LCS by pyridyl gemini surfactants with different alkyl chains. Materials Chemistry and Physics 2020, 240, https://doi.org/10.1016/j.matchemphys.2019.122156. 